\title{
Aportación a la historia del léxico del s. XVIII: análisis de las Obras de Mengs de D. José Nicolás de Azara ${ }^{1}$
}

\author{
Pilar LÓPEZ MORA \\ Universidad de Málaga \\ lomora@uma.es
}

\begin{abstract}
RESUMEN
A partir del estudio de las Obras de D. Antonio Rafael Mengs, primer pintor de Cámara del Rey, publicadas por D. José Nicolás de Azara a finales del siglo XVIII, la autora de esta investigación realiza, en primer lugar, una caracterización lexicológica de este tratado teórico-artístico, prestando especial atención al léxico propio del género al que pertenece. A continuación, se analizan los neologismos del siglo XVIII encontrados en el texto.
\end{abstract}

Palabras clave: Lexicología, Lingüística histórica, Historia de la lengua española, José Nicolás Azara, El español del siglo XVIII.

\begin{abstract}
This research consists of a lexicological characterization of the Obras de D. Antonio Rafael Mengs, primer pintor de Cámara del Rey, a theoretical treatise, published in the late eighteenth century. The author of this paper analyzes both the lexicon of the Arts and the 18 th century neologisms found in the text.
\end{abstract}

\footnotetext{
${ }^{1}$ El presente trabajo forma parte de los resultados de los proyectos de investigación del Plan Nacional Desarrollo de un tesauro terminológico-conceptual (TTC) de los discursos teórico-artísticos españoles de la Edad Moderna, complementado con un corpus textual informatizado ( $1^{a}$ fase) [HUM2005-00539] y Desarrollo de un tesauro terminológicoconceptual de los discursos teórico-artísticos españoles de la Edad Moderna y del corpus textual informatizado ATENEA (2 ${ }^{a}$ fase) [HAR2009-07068], dirigidos por la Dra. D ${ }^{\mathrm{a}}$. Nuria Rodríguez Ortega.
} 
Key words: Lexicology, History of Spanish Language, Historical Linguistics, José Nicolás Azara, $18^{\text {th }}$ Century.

SUMARIO: 1. Introducción. 2. Estudio léxico. 2.1. Caracterización lexicológica del texto. 2.2. Las voces del siglo XVIII en las Obras de Mengs. 3. Conclusiones.

\section{Introducción}

En el corpus de obras teórico-artísticas de la Edad Moderna recopilado en el marco del proyecto ATENEA ${ }^{2}$, hallamos la segunda edición de las Obras de D. Antonio Rafael Mengs, primer pintor de Cámara del Rey realizada por José Nicolás de Azara ${ }^{3}$. Este impresionante volumen es una compilación que incluye los tratados estilísticos del pintor sajón, precedidos por la "Noticia de la vida y obras de don Antón Raphael Mengs" y completados por no pocas notas y comentarios de D. José Nicolás de Azara, amigo y protector del pintor y responsable de la obra.

La primera edición del libro se publica en Madrid en 1780, pocos meses después de la muerte de Mengs, como un homenaje que Azara quisiera brindarle. En 1783, aparece la edición italiana también a cargo de Azara. La edición italiana contiene textos que no se habían incluido en la española, adiciones de $1792^{4}$ que sí se hallan en la edición de 1797, que es la que manejo para mi estudio.

Antonio Rafael Mengs (Ausig, 1728) ${ }^{5}$ es uno de los más importantes representantes del período neoclásico en Europa. Conocido como el pintor filósofo ${ }^{6}$, Mengs estudió obsesiva y minuciosamente a los pintores renacentistas con el afán de perfeccionar su estilo mediante el dominio de una técnica pictórica impecable, sumada a un ideal de belleza que remite a la Antigüedad Clásica como único modelo ${ }^{7}$. Las ideas estéticas de Mengs, inmortalizadas en la traducción realizada por Azara, tienen la huella de la influencia de su también amigo Winckelmann ${ }^{8}$.

Para la posteridad, Mengs es más importante como teórico del arte que como pintor, pues, en palabras de Sánchez Cantón, "Mengs pintando fué esclavo del

\footnotetext{
${ }^{2}$ El proyecto ATENEA (www.proyectoatenea.es) tiene como meta la creación de un archivo digital de textos de teóricos sobre las artes durante los siglos XVI, XVII y XVIII y la creación de un tesauro terminológico-conceptual, vid. N. Rodríguez Ortega (2009) y P. López Mora (2010).

${ }^{3}$ R. Mengs (1797), en adelante Obras de Mengs.

${ }^{4}$ J. I. Tellechea Idígoras (1972).

${ }^{5}$ Vid. la "Noticia de la vida y obras de don Antón Raphael Mengs", escrita por Azara en 1780 e incluida en las Obras de Mengs.

${ }^{6}$ N. Cinelli (2013).

${ }^{7}$ M. Hidalgo (2014).

${ }^{8}$ Creador de la moderna crítica de Arte en el Neoclasicismo alemán, autor de la Historia del Arte en la Antigüedad o de las Reflexiones sobre la imitación del Arte griego en pintura y escultura. Vid. X. Castañer (2003).
} 
Mengs que pensaba" ${ }^{9}$, como lo expresa Cinelli, "Mengs fue teórico antes que pintor"10.

Sea como fuere, desde un punto de vista lingüístico, el texto no es responsabilidad de Mengs tanto como de su editor y traductor José Nicolás de Azara, que, además de traducir las partes de las Obras de Mengs escritas en alemán, italiano o francés, hubo de corregir las que Mengs escribiese en castellano, lengua en la que "no tenía la mayor práctica de escribir"11. Algo que menos amablemente expresa Tomás de Iriarte en una carta dirigida a Azara en enero de 1781:

[...] comprendiendo yo muy bien quánto habrás tenido que vencer para desentrañar aquel Caos, y dar a entender en la forma posible lo que Mengs dejó apenas bosquejado entre las obscuras sombras de su estilo intrincado y metafísico [...]. La verdad que tienes destino de trabajar en obras agenas de difícil lucimiento, y cuyos autores ignoraron el arte de hablar y de escribir, sin cuyos requisitos no se pueden componer libros ${ }^{12}$.

Azara fue embajador en Parma, París y Roma, y siempre mantuvo contacto con el ambiente cultural y artístico representativo de la Ilustración ${ }^{13}$. Erudito, cultivado en el campo de las Bellas Artes, "mecenas, coleccionista y bibliófilo"14, Azara no solo es un respetado traductor ${ }^{15}$, es también un teórico del arte con sus propias ideas estéticas, reconocido precisamente por su "Comentario al tratado de la Belleza de Mengs"16. Así, al no conocerse "obra enteramente suya"17, la que nos ocupa podrá considerarse su más extenso legado literario $^{18}$, el cual hace gala de una

${ }^{9}$ F. J. Sánchez Cantón (1927), p. 5.

${ }^{10}$ N. Cinelli (2010), p. 278.

${ }^{11}$ Comentario de Azara acerca de la carta que Mengs escribe a D. Antonio Ponz y que justifica sus retoques estilísticos y correcciones del original (Obras de Mengs, p. 199).

${ }^{12}$ Carta incluida como Documento $V$ en J. I. Tellechea (1972), pp. 62-63, cita en p. 62.

${ }^{13}$ J. N. de Azara (1804), B. S. Castellanos de Losada (1850) y G. Sánchez Espinosa (2000).

${ }^{14}$ N. Cinelli (2012), p. 209.

${ }^{15}$ La labor como traductor de Azara es mencionada con elogio por Vargas Ponce o Covarrubias, vid. M ${ }^{\mathrm{a}}$ J. García Garrosa y F. Lafarga (2004), p. 48.

${ }^{16}$ Sobre la consideración y respeto que de esta faceta de Azara tiene, entre otros, su coétaneo Arteaga, vid. J. Checa Beltrán (2004), pp. 23 y 27.

${ }^{17}$ Palabras de Bourgoin en su prólogo a la recopilación de las cartas de Azara a Roda (J. N. de Azara, 1804, pp. 18-19).

${ }^{18}$ No obstante, habremos de tener en cuenta que durante la publicación de las Obras de Mengs Azara, que entonces se hallaba en Roma, cuenta "con la colaboración madrileña de Eugenio de Llaguno, que impuso algunos retoques estilísticos sobre el manuscrito de Azara" (G. Sánchez Espinosa, 2000, p. 10). Es más, a la luz del análisis y publicación de la correspondencia mantenida entre Azara y Llaguno, realizado por Tellechea Idígoras, tendríamos que pensar que la participación de Llaguno no se redujo a una corrección 
impresionante riqueza léxica, plena de cultismos, neologismos, así como de los tecnicismos propios de la lengua de especialidad a la que pertenece.

\section{Estudio léxico}

El texto de Mengs-Azara constituye un magnífico recurso para el estudio del léxico del español moderno, aprovechable en dos sentidos:

1) En interés de la reconstrucción del léxico propio del género discursivo al que el texto pertenece; el discurso teórico-artístico se nutre, como lengua de especialidad, de préstamos de lenguas modernas, términos cultos rescatados del olvido o de nuevo cuño ${ }^{19}$, así como de la construcción patrimonial de nuevas unidades ${ }^{20}$.

2) En tanto producto de una evolución lingüística que llega a los albores del siglo XIX y que recoge la herencia perteneciente al español culto del momento, culminación de siglos de evolución y crecimiento. El siglo XVIII es en sí mismo una etapa de transición entre el español clásico y el moderno cuyo estudio está cobrando una relevancia sin precedentes en los últimos tiempos ${ }^{21}$.

De especial interés será la documentación de algunas voces que existieron en los textos de esta tradición y que no han prosperado o se han constreñido en el uso a una cronología o a un limitado elenco de autores, como veremos en el apartado correspondiente. No obstante, nuestra investigación buscará sobre todo entresacar qué deja el siglo XVIII para la posteridad en el léxico de las Artes.

Para la documentación y el rastreo de la historia de las voces contamos hoy en día con herramientas magníficas como son los corpus académicos (CORDE y CREA), el Portal del Léxico Español (PLE), el Corpus del español y el NTLLE, para comprobar la inclusión de las voces en los diccionarios académicos, así como un numeroso grupo de corpus disponibles en línea o en versiones electrónicas en los que se recopilan los textos de la historia del español ${ }^{22}$. Por otra parte, se están digitalizando miles de libros en la biblioteca virtual Google Books, lugar en el que se puede disponer de la versión electrónica del algunos ejemplares prácticamente inaccesibles ${ }^{23}$. En cualquier caso, esta cantidad de recursos no garantiza la

estilística, sino que llegó a eliminar partes del original que pudieran "contribuir al descrédito de España" (J. I. Tellechea, 1972, p. 53) y, recriminando a Azara que no modificase la edición italiana, escribe "quitémoslo de un libro que no es de nadie" (J. I. Tellechea, 1972, p. 60), en referencia a la versión española de las Obras de Mengs.

${ }^{19}$ M. Alvar (1982).

${ }^{20} \mathrm{M}^{\mathrm{a}}$ A. Martín Zorraquino (1997).

${ }^{21} \mathrm{M}^{\mathrm{a}}$ T. García-Godoy (2012).

${ }^{22}$ Vid. G. Clavería (2012), G. Clavería y M J. Mancho (2006) y Fajardo (2012).

${ }^{23}$ Acerca de la librería virtual Google Books y su cooperación con numerosas bibliotecas universitarias, vid. el artículo de K. Bergquist (2006). El proyecto Google Library cuenta con la colaboración de más de 40 grandes bibliotecas de todo el mundo, la mayor parte de 
reconstrucción de la historia del léxico, solamente la facilita y, por ello, hemos de seguir siendo tan cautos como nuestros antecesores en estas labores de recuperación del patrimonio léxico y la fijación absoluta de los datos ${ }^{24}$. En nuestro caso, hemos recurrido a todas estas herramientas, principalmente el corpus académico CORDE, que será la fuente de la primera documentación, siempre que no se anote lo contrario, para datar la entrada de las voces en el español ${ }^{25}$.

\subsection{Caracterización lexicológica del texto}

2.1.1. Entre los elementos léxicos que conforman nuestro texto tienen una importancia relativa los arabismos, que son en su mayoría propios del vocabulario referente al Arte ${ }^{26}$. En las Obras de Mengs, entre otros, contamos los préstamos alarde, alcántara, albañil, alcázar, alhaja, aljibe, almoneda, ardid, cequí, halagar, halagüeño, laca, maravedí, marfil, mezquino, naranja. Casi todos ellos han sobrevivido al paso de los siglos desde su entrada al idioma; con la excepción de alguno, como cequí, que se refiere a la moneda veneciana, cuyo uso es ya muy escaso en el momento en que Azara publica las Obras de Mengs.

De entre los arabismos propios del tipo de lengua al que pertenecen las Obras de Mengs, interesa la historia de la voz laca, cuya acepción 'color rojo' parece ser propia del siglo XVIII y, por ello, la estudiaremos en el epígrafe correspondiente.

2.1.2. Para una caracterización lexicológica del texto de Mengs-Azara habremos de señalar el abundante léxico culto. En un análisis no exhaustivo, hemos recopilado una considerable lista de helenismos ${ }^{27}$, entre los cuales alabastro, cinabrio, diáfano, jónico, mármol, mausoleo, mecánico, símbolo y yeso son términos relacionados directamente con las Artes ${ }^{28}$. Además de estos, son de nuestro interés los que, aun siendo términos de la anatomía (acromion, anatomía, embrión, fisionomía), de la geometría (ángulo, diámetro, geometría, pirámide) o de

ellas universitarias. Se puede consultar el listado de las mismas en el siguiente vínculo: http://books.google.com/googlebooks/library/partners.html

${ }^{24}$ Vid. el estudio inaugural del léxico del siglo XVIII de G. Salvador (1973).

${ }^{25}$ Sobre la metodología de la datación en los estudios de la historia del léxico, vid. Fajardo (2006).

${ }^{26}$ Ya advirtió M. Alvar (1982), p. 130, que en su estudio sobre las voces incluidas en el Diccionario de términos artísticos de Morales y Martín los arabismos eran numerosísimos solo porque se fija en las palabras que constituyen la letra A y reconoce que, de observar cualquier otra letra del alfabeto, esta abundancia disminuiría de modo muy notable.

${ }^{27}$ Acromion, alabastro, alegoría, anatematizar, anatomía, analogía, ángulo, armonía, atleta, cinabrio, diáfano, diámetro, embrión, fantasía, fisionomía, geometría, heroico, jónico, laberinto, lira, magro, mármol, mártir, martirio, matemática, mausoleo, mecánico, metáfora, misterio, místico, mitología, ninfa, paradoja, pirámide, poesía, policía, práctica, proemio, profeta, profético, sábana, sátiro, símbolo, sofisma, yeso.

${ }^{28}$ Todos ellos están recogidos en J. L. Morales y Marín (1982). 
la filosofía (anatematizar, mitología, paradoja) sirven a los propósitos de la obra que necesita de estos artificios léxicos para expresarse propiamente.

2.1.3. Para los latinismos ${ }^{29}$ si bien, no se ha realizado una periodización exhaustiva, sí hemos separado grosso modo, los del s. XIII de los de fines del XIV y XV. Más abajo se recogen los que datan de los Siglos de Oro. Entre los primeros, los documentados en los siglos XII y XIII, que se registran en nuestro texto ${ }^{30}$, son voces terminológicas figura, luminar, monumento, natural, obscuridad, ornamento, proporción, restauración, restaurar, triangular y volumen.

Más numerosa es la lista de latinismos cuya primera documentación se halla en textos de los siglos XIV y XV ${ }^{31}$, a partir de los cuales el vocabulario terminológico

${ }^{29}$ Para la definición de latinismo y la diferencia metodológica con el concepto de cultismo, remitimos al excelente trabajo G. Clavería (1991).

${ }^{30}$ Adulterar, arbitrario, benignidad, coyuntura, cuestión, devoto, discipulo, diversidad, doctrina, examinar, excelente, figura, fundamento, honestidad, humanidad, idolatria, idolo, ignorancia, iluminar, instruir, laudable, lector, liberal, liberto, lícito, luminar, magnificencia, majestad, mansedumbre, mérito, ministerio, miseria, monumento, multiplicación, multiplicar, multitud, murmurar, mutación, natura, natural, naturaleza, naturista, negligencia, negligente, nonagésimo, notario, notorio, obediencia, obscuridad, occidental, occidente, olímpico, omnipotente, oráculo, ornamento, paganismo, pedestre, perfecto, perpetuo, primogénito, privilegio, prodigioso, propiedad, proporción, prolijidad, pudor, racional, rectificar, reliquia, reputar, restauración, restaurar, robusto, rústico, sabiduria, sacrificar, sacrificio, selva, sepultar, secuaz, simulacro, suavidad, substancia, suntuoso, superfluidad, sutil, tenebroso, testimonio, transformar, translación, triangular, triángulo, túnica, ungüento, vanidad, volumen.

${ }^{31}$ Adusto, aéreo, ápice, arbitrario, artifice, atributo, beneficencia, cadáver, confutar, conjetura, consonancia, convención, corpóreo, disipar, disonancia, dócil, elevación, eludir, émulo, equívoco, erróneo, erudito, esculpir, escultura, esencial, esfera, esmero, espectáculo, especulación, esplendor, estímulo, exhalar, explicar, exponer, expresar, exquisito, extirpar, fábula, facundia, fecundo, ferocidad, fermentación, fermento, fertilidad, filosófico, fisonomía, flexión, fomentar, fragmento, frenético, fructificar, fugitivo, funeral, galería, gratitud, heterogéneo, honorario, humillación, ilicito, ilustrar, ilustre, implicar, ímprobo, impropiedad, imprudencia, impunidad, incidencia, inclemencia, incompatible, indocto, industrioso, infalible, inferir, infundir, insigne, insinuación, integridad, inteligible, intersticio, inutilidad, irracional, irregularidad, lascivo, límite, lineamento, literato, longitud, magisterio, magistral, magnitud, máquina, mediocridad, meditación, meditar, melancólico, miserable, modestia, modesto, modificación, monstruoso, músculo, musculoso, novedad, objeción, oblicuo, observancia, obtuso, ocupación, ofuscar, opaco, opresión, óptico, opulencia, opulento, oratoria, ornato, pálido, partícula, penetración, penitente, penúltimo, perpendicular, perpetuidad, perspectiva, plagiario, pómez, pontificado, pontífice, pórtico, posteridad, preámbulo, precepto, prerrogativa, preservar, pretensión, prevalecer, preventivo, primitivo, privativo, prodigio, profano, profesar, profusión, progreso, prominente, propagar, protector, prurito, purpúreo, pusilánime, raciocinar, raciocinio, 
de las Artes se enriquece con las voces: artífice, corpóreo, esculpir, escultura, galeria, intersticio, lineamento, longitud, magnitud, oblicuo, obtuso, opaco, óptico, ornato, perpendicular, perspectiva, pómez, purpúreo, reflexión, terso, transparente y uniforme.

2.1.4. Neologismos áureos: latinismos y neolatinismos; helenismos y neohelenismos.

En el caso de las creaciones léxicas cultas de los Siglos de Oro, utilizamos la denominación neologismos áureos en alusión a las voces que se acuñan partiendo de los formantes cultos integrados en el idioma o que se toman directamente del latín o el griego para resolver las necesidades de las lenguas en su desarrollo. Siguiendo a Verdonk ${ }^{32}$, hemos querido dar una datación renovada de los términos, pues nos ha parecido de interés subrayar la génesis de unas voces cuyo nacimiento para el español está tan cerca de la época en que se redactan las Obras de Mengs:

abolición (c1550, Alonso de Santa Cruz), acrimonia (1527-61, F. Bartolomé de las Casas), adjunto (1562, Jerónimo Zurita), afectación (1533-36, Garcilaso de la Vega), computar (1527-50, F. Bartolomé de las Casas), contorsión (1606, Juan Alonso de los Ruices y de Fontecha), convulso (1606-11, Juan Méndez Nieto), cutis (1591, Juan de Cárdenas), chimérico (1528, Francisco de Osuna), decadencia (1592, Luis Collado), decoroso (1585, Juan de Arfe y Villafañe), delinear (1560, F. Luis de Granada), deplorable (1632, Chrisóstomo Henríquez), desacreditar (1521, F. Antonio de Guevara), designio (1523, Antonio Brito), despropósito (1524, F. Luis de Granada), digresión (1527-50, F. Bartolomé de las Casas), discernimiento (1607, S. Juan Bautista de la Concepción), disertación (1570, Pedro Rodríguez Campomanes), divinizar (1595, F. Juan de los Ángeles), elíptico (1599-1622, Conde de Villamediana), energúmeno (1599-1601, Pedro de Ribadeneira) ${ }^{33}$, irrupción (1649-51, Conde de Rebolledo), jeroglifico (1563, Manuel Denis), jurisprudencia (1550, Arce de Otárola), latinizar (1615, Tirso de Molina), lúgubre (1527-50, F. Bartolomé de las Casas), majestuoso (1535-1622, Anónimo), maledicencia (1538, F. Luis de Granada), mecanismo (1654-58, Jerónimo de Barrionuevo), método (1524, Anónimo), nimio (1597-1645, Francisco de Quevedo), oblicuidad (c1527, Alonso de Chaves), oleoso (1573, Jerónimo Muñoz), opacidad (c1560-a1578, Francisco de Aldana), ovado (1565, Fadrique de Zúñiga y Sotomayor), oval (1540-50, Pedro Mejía), óvalo (14931564, Anónimo), paralelogramo (1585, J. de Arfe y Villafañe), panegírico

radicar, reflexión, reparable, repugnar, reverberación, ridículo, rótulo, rusticidad, sensibilidad, solicitud, sólido, sublime, sublimidad, subordinada, subsistir sucinto, sujeción, superfluo, superstición, suplicio, temeridad, temperamento, terso, testificar, tiranizar, tolerar, tortuosidad, transparente, transportar, tumultuoso, uniforme, universal, venerable, veneración, verisímil, vindicar, vituperar.

${ }^{32}$ R. Verdonk (2004).

${ }^{33}$ PLE S.V. 
(1535-1557, Gonzalo Fernández de Oviedo), panegirista (1625, F. Hortensio Paravicino), pentágono (1567, Pedro Núñez), percepción (c1535-75, Diego Hurtado de Mendoza), predilección (1648, N. Fernández de Castro ${ }^{34}$ ), problemático (1624, Tirso de Molina), prófugo (c1560-78, Francisco de Aldana), propensión (1536-85, Francisco Morán de la Estrella), prototipo (c1530-39, F. Dionisio Vázquez), proyecto (c1527-61, F. Bartolomé de las Casas), refracción (1580, Fernando de Herrera), semicírculo (1526, Diego de Sagredo), semidiámetro (1537-56, Tratado anónimo de Arquitectura), simbólico (1569, Bernardo Pérez de Vargas), simetría (1535-57, Gonzalo Fernández de Oviedo), simétrico (1599-1622, Conde de Villamediana), solidez (c1619, Luis Cabrera de Córdoba), tétrico (c1550, Arce de Otárola), tórax (1589, Juan de Pineda) ${ }^{35}$, transparencia (1527-50, F. Bartolomé de las Casas), translucir (1527-50, F. Bartolomé de las Casas), trivial (c1550, Arce de Otárola), uniformar (a1622, Conde de Villamediana ${ }^{36}$ ), voluminoso (1641, Sanz del Castillo).

De ellas, consideramos que son específicas de las Artes y disciplinas próximas las siguientes: cutis, delinear, elíptico, oblicuidad, oleoso, opacidad, ovado, oval, óvalo, paralelogramo, pentágono, perspectiva, prototipo, proyecto, semicírculo, semidiámetro, simetría, simétrico, solidez, transparencia, translucir, uniformar y voluminoso.

2.1.5. Préstamos de lenguas románicas

2.1.5.1. En primer lugar, destaca cualitativa y cuantitativamente el italianismo léxico de las Obras de Mengs. Los préstamos del italiano, en su mayor parte debidos a la incontestable influencia que Italia supuso para los demás países europeos en el terreno de las Artes ${ }^{37}$, son en nuestro texto numerosísimos; en muchos casos, términos de la Arquitectura y la Pintura: arlequín, artesano ${ }^{38}$, bambochada, belleza, bronce, capricho, caricatura, claroscuro, colorir, cúpula, diseño, escorzado, escorzo, estuco, fachada, frontispicio, fresco, galería, gofo, logia, lustre, modelo y modelar, mórbido y morbideza (en Pintura 'blandura en las

${ }^{34}$ La voz está ya en Autoridades y, si bien CORDE no la recoge hasta un texto de 1743, las documentaciones son muchas, al menos desde el s. XVII. Así, la documentación a la que nos referimos está en N. Fernández de Castro (1648).

${ }^{35}$ Este préstamo griego de la anatomía se castellaniza en tórace, tóraz, adaptación formal con la que se halla en nuestro texto o en el diccionario de Terreros. Aclara C. García Jáuregui (2010), p. 72, n. 52, que la consolidación de tórax se debió a la necesidad de la lengua de especialidad de evitar el uso equívoco por pecho.

${ }^{36}$ Autoridades s.v.; DCECH s.v. forma.

${ }^{37}$ J. Terlinger (1967), p. 271.

${ }^{38}$ Matiza G. Colón (1967), p. 228, que este italianismo, al igual que lustre, penetra por vía del catalán. 
carnes'), mosaico ${ }^{39}$, muralla, parangonar, pátina, peto, pilastra, pintoresco, pulimento, relieve, retratar, retrato ${ }^{40}$, secatura, torso, tráfico ${ }^{41}$, zócolo. Algunos de estos, como relieve y fresco, son en realidad calcos semánticos pertenecientes al ámbito de la Pintura ${ }^{42}$.

En cuanto a su datación, las voces bambochada, caricatura, pátina, pintoresco y secatura se registran en el siglo XVIII, por lo que las estudiamos en el epígrafe correspondiente.

No obstante, el italianismo de las Obras de Mengs no se debe tan solo al uso de un léxico específico de las Artes más o menos novedoso y especializado: la influencia del italiano en Mengs-Azara queda patente en algún desliz, como el uso del italiano zócolo por el esp. zócalo:

En la inferior hay ventanas quasi redondas; y por eso Corregio fingió una especie de zócolo que gira alrededor como anexándose, y dexa lugar para que entre las ventanas quepan los Apóstoles que están puestos a uno y a dos; y no obstante que algunos caen sobre la misma línea de los ángulos, se hallan tan bien colocados y escorzados, que no ofenden nada la vista, y parecen plantados perpendicularmente sobre la cornisa. Sobre dicho zócolo hay repartidos varios jóvenes a manera de Ángeles, pero sin alas, que encienden algunos blandones (Obras de Mengs, p. 292).

O en la selección de un vocabulario general en muchos casos debido a la traducción desde el italiano y del que se es muy consciente. Un notable ejemplo de ello está en el siguiente pasaje de las Obras de Mengs:

En el Vaticano hay una Venus muy mediana, y quasi gofa ${ }^{\mathrm{I}}$ cuya cabeza no se puede dudar sea suya, porque está íntegra, y dicha cabeza es muy bella, e igualarla de Niobe (Obras de Mengs, p. 159).

En este fragmento de la carta de Mengs a Monseñor Fabroni sobre el grupo de Níobe, probablemente escrita en italiano, se usa la voz gofa en cursiva, femenino de gofo 'rudo, grosero', procedente del italiano goffo 'che manca di disinvoltura o di buon gusto ${ }^{\prime 3} \mathrm{y}$, aunque efectivamente existe en español ${ }^{44}$, Azara se apresura a

${ }^{39}$ Vid. J. Terlinger (1967); A. Nocentini (2010), s.v. mosaico; DCECH s.v. musa.

${ }^{40}$ DCECH s.v. traer; A. Nocentini (2010), s.v.

${ }^{41}$ DRAE s.v.

${ }^{42}$ N. Rodríguez Ortega (2007).

${ }^{43}$ A. Nocentini (2010) s.v.

${ }^{44}$ Se documenta en 1517 en texto de Tomás Naharro (DCECH s.v.) y se incluye en los diccionarios al menos desde 1591 (en la Bibliotheca Hispanica de Percivale) en adelante. 
aclararla en nota como extranjerismo: "Gofo en Italiano quiere decir una cosa muy ordinaria, ridícula y fuera de proporción" ${ }^{45}$.

2.1.5.2. No menos interesantes, los galicismos nos regalan nomenclaturas específicas de multitud de ámbitos: bermellón, blandón, carmín, cornisa ${ }^{46}$, dama, despachar, desmayarse, dibujar, estofa 'tejido sedoso', estoque, gabinete, galán, galopín, melindroso ${ }^{47}$, moda, perfil, pedestal, pitipié, sanguino ${ }^{48}$, servilleta, tapiz, violeta. Hemos prestado atención más adelante en nuestro estudio a los tecnicismos desmayado y gabinete. Asimismo, parece digno de señalar que el galicismo moda, documentado en el español desde 1579, no arraigaría plenamente en el idioma hasta bien entrado el siglo XVIII ${ }^{49}$.

2.1.5.3. En distinta proporción, mencionaremos algunos de los catalanismos de las Obras de Mengs, por ejemplo: el término bosquejar ${ }^{50}$, del cual, por reanálisis, deriva bosquejo, forastero, pincel, retablo, rozagante, semblante y tafetán ${ }^{51}$.

2.1.6. Lógicamente, en esta caracterización del texto que nos ocupa, hemos de subrayar el inabarcable vocabulario patrimonial: aquel nacido a partir de los procedimientos de creación léxica propios: derivación y composición, a partir de bases y afijos patrimoniales, de los que bastidor, blanquizco, cartón, copista, descorrección, diseñador, encolar, ennegrecer, envilecimiento, espinazo, largura, negrizco, pastoso, pincelada, porosidad, portada, prendimiento, realzar, redondez, refinar, repintar, retocar, retoque, revestir, ropaje o sobrepuerta son solo unos pocos ejemplos. Dados los límites del presente trabajo, en el apartado de la creación léxica patrimonial solo atenderemos brevemente a un par de voces que dejan constancia del potencial de las Obras de Mengs para la reconstrucción de la historia del léxico: negrizco y descostradura.

2.1.6.1. Es el campo semántico del color de gran interés en nuestro texto, como es fácil comprobar tan solo en las voces bermellón, carmín, laca, rojizo, sanguino, únicamente para indicar matices de rojo.

\footnotetext{
${ }^{45}$ Obras de Mengs, p. 159, n. 1.

${ }^{46}$ Helenismo que, según el DRAE, procede del provenzal cornís. Cf. J. Terlinger (1967) que considera esta voz italianismo al igual que F. García Salinero (1968).

${ }^{47}$ DCECH s.v. melindre; E. Varela Merino (2009), pp. 1557-1558.

${ }^{48}$ Según D. Pharies (2002), p. 342, el sufijo -ino refleja en este caso una procedencia foránea, probablemente el francés sanguin. Sanguino es voz muy antigua en español para denominar el color rojo oscuro (vid. E. Martinell, 1986, y R. M. Duncan, 1968, pp. 463-464. 49 Vid. P. Álvarez de Miranda (1992), pp. 655-659 y E. Varela Merino (2009), p. 1607.

${ }^{50}$ A. M. Alcover y F. de B. Moll (1978).

${ }^{51}$ J. Coromines (1980-91), s.v. tafetà; D. Pharies (2002), p. 65.
} 
El léxico de la Pintura nos regala algunas rarezas en el apartado de la creación léxica patrimonial. En este sentido, recogemos, junto a blanquizco 'blanquecino', el adjetivo negrizco, ambos de escasísima frecuencia de uso y especiales en su morfología, como explica Pharies ${ }^{52}$ con respecto al sufijo -izco, cuya formación atribuye a un cruce analógico con blancuzco y negruzco:

Por máxima general usaba poco los colores amarillos y rojos, entendía muy bien el efecto que hace la oscuridad en los colores, aniquilándolos y convirtiéndolos en pardos y negrizcos (Obras de Mengs, p. 106).

Con respecto a las escasas documentaciones de la voz negrizco, es curioso el hecho de que en CORDE la única ocurrencia esté en los Apuntamientos para la Historia Natural de los páxaros del Paragüay y Río de la Plata (1802-1805), de Félix de Azara, hermano de Nicolás de Azara.

2.1.6.2. La voz descostradura 'desconchadura', rara, derivaría del adjetivo descostrado con sufijo -ura. No hay registro de ella en CORDE, donde sí que aparecen descostrado y descostrar. Tampoco se recoge esta voz en los diccionarios consultados, si bien hemos localizado la forma decostradura, donde se alterna el prefijo de-/des-. Decostradura se documenta en Hornkens (1599) como 'chapelures; stricturae crustrarum'; también está en Palet, Oudin, Vittori, Minsheau, etc. con significado similar ${ }^{53}$. En la Enciclopedia del idioma, la hallamos como la 'acción de quitar la $\operatorname{costra}^{54}$, sentido muy alejado del significado adoptado por la voz en nuestro texto:

Este quadro había padecido algunas descostraduras, y se aumentaron en el transporte de Módena a Dresde; pero con el cuidado que se tuvo de conservar los fragmentos se pudo componer excelentemente: por el Sr. Sedrizi, Pintor del Rey Augusto (Obras de Mengs, p. 298, n. 1).

La documentación de la forma descostradura es muy escasa; tan solo la hemos localizado en tres libros de los siglos XVIII y XIX ${ }^{55}$.

2.1.7. Por último, el crecimiento de una lengua ocurre también al dotar a las voces existentes de nuevos valores semánticos en una evolución idiomática natural, que se agudiza en las lenguas de especialidad las cuales se sirven de palabras de la

${ }^{52}$ D. Pharies (2002), p. 353.

${ }^{53}$ Vid. L. Nieto y M. Alvar Ezquerra (2007), s.v. decostradura.

${ }^{54}$ M. Alonso (1958) s.v.

${ }^{55}$ J. Díaz y F. Lorente (1836), M. de Valbuena (1826) y P. García de la Huerta (1795). 
lengua común para cubrir las necesidades propias de la precisión técnica que exigen. Así, el surgimiento de nuevos valores en palabras existentes mediante deslizamientos semánticos y metáforas enriquecen tanto o más un léxico especial ${ }^{56}$; de este fenómeno ofreceremos a continuación algunos ejemplos ilustrativos: desmayado, linterna, masa, plano, plantado, punzón y subido.

2.1.7.1. Desmayado. En las Obras de Mengs, la voz desmayarse (del fr. ant. esmaiier, 'perturbar, desfallecer') no solo adopta el significado general que tiene en la lengua común, sino que, al menos en una ocasión, se muestra en un uso especializado como adjetivo que se aplica al 'color bajo y apagado ${ }^{157}$ y que ya se recoge en el Diccionario de Autoridades ${ }^{58}$. Se trata de una especialización semántica de gran calado en el tipo de lengua que nos ocupa:

Conforme a este es la soberbia obra a fresco del Cason del Retiro, y muchos quadros de los que hay en Palacio; pero en otras obras que después hizo en Madrid se apartó algo de dicho Estilo, mezclando figuras vestidas al modo de Pablo Veronés, y pintando más desmayado de tintas y clarobscuro (Obras de Mengs, $\mathrm{p}$. 225).

2.1.7.2 Linterna interesa en tanto que adaptación semántica desde su significado 'farol portátil con una sola cara de vidrio y un asa en la opuesta' (DRAE s.v.) y que, como término propio de la Arquitectura, significa 'fábrica de figura varia pero siempre más alta que ancha y con ventanas, que se pone como remate en algunos edificios y sobre las medias naranjas de las iglesias' ${ }^{59}$.

García Salinero da como primera documentación de esta acepción un texto de Herrera de $1589^{60}$. El rastreo en CORDE adelanta esta datación de modo poco significativo (1579); mas no deja de ser interesante, con respecto a su afianzamiento en el idioma, que en las Obras de Mengs su aparición venga acompañada de una paráfrasis que, aun pudiendo ser remate estilístico, hace las veces de aclaración del tecnicismo:

La primera obra que este grande hombre pintó en Parma fue a fresco la cúpula de la Iglesia de San Juan de Padres Benitos, y las quatro pechinas, y asimismo la tribuna sobre el Altar mayor. La cúpula no tiene linterna, esto es, abertura en el centro, ni ventana alguna a los lados (Obras de Mengs, p. 287).

\footnotetext{
${ }^{56}$ M. Alvar (1982), pp. 126-128.

57 J. L. Morales y Marín (1982).

${ }^{58}$ RAE (1726-39). En adelante Autoridades.

${ }^{59}$ J. L. Morales y Marín (1982).

${ }^{60}$ F. García Salinero (1968), s.v.
} 
2.1.7.3. Otro cambio semántico apreciable en el tratado de Mengs-Azara es el que ocurre en la voz masa que en su uso terminológico de la Pintura ${ }^{61}$ adopta un sentido que se aclara en una nota:

Masa en términos de Pintura quiere decir el sitio donde se junta una gran quantidad de luz, o de sombra. Quando un quadro se ve a poca luz, solamente se distinguen en él los claros más fuertes: y aquellos son masas de luz (Obras de Mengs, p. 37, n. 1).

2.1.7.4. El término plano es un cultismo geométrico que con la acepción 'superficie plana' (DRAE s.v. 4), heredera del lat. PLANUM ${ }^{62}$, tiene su primera documentación, según García Salinero, en un documento de 1514 perteneciente a la recolección de Abizanda y Broto (1915): "Que el dicho retablo a de ser muy bien encolado y sus planos encanyamados y enguixados de su lado grueso"63.

Este término adopta en Pintura el sentido de 'superficie donde se deben disponer los objetos en una composición para dotarla de perspectiva' ${ }^{64}$. Uno de los numerosos pasajes en que el tratado de Mengs-Azara incluye esta voz destaca por su interesante oposición entre plano y escorzo:

Habiendo vencido la mayor dificultad del Arte, que es la imitación de la simple verdad, algunos hábiles Profesores, como Másacio, Juan Bellino, y Andrés Manteña, los quales hallaron el modo de expresar los diferentes planos y escorzos, esto es, lo que en términos facultativos llaman los Italianos avantiindietro, [...] (Obras de Mengs, p. 308).

2.1.7.5. Tanto el adjetivo plantado como el verbo del que desciende, plantar 'la acción de estar de pie una figura ${ }^{165}$, suponen dos derivados del tecnicismo planta 'diseño en que se da idea para la fábrica o formación de algo' ${ }^{66}$, el cual, en su acepción terminológica, es probablemente préstamo semántico del italiano ${ }^{67}$.

Además de la documentación proporcionada en el Museo pictórico y escala óptica de Palomino y Velasco de $1715^{68}$, la búsqueda en el corpus lingüístico de ATENEA ofrece testimonios más tempranos de plantar y plantado. El primero, de

${ }^{61}$ Vid. J. L. Morales y Marín (1982), s.v. 3; M. Bazzi (1965) s.v.

${ }^{62}$ P. G. W. Glare (2005), s.v. PLANUM-I 1.b: "(Geom.) 'a plain figure"'.

${ }^{63}$ F. García Salinero (1968), s.v.

${ }^{64}$ Vid. L. Grassi y M. Pepe (1994) s.v. piani degradati y piano prospettivo.

${ }^{65}$ J. L. Morales y Marín (1982).

${ }^{66}$ J. L. Morales y Marín (1982).

${ }^{67} \mathrm{M}^{\mathrm{a}}$ I. Martín Fernández (1988), p. 94.

${ }^{68} \mathrm{Vid}$. J. L. Morales y Marín (1982) s.v. plantado, planta. 
1633, en los Diálogos de la Pintura de Vicencio Carducho y, no mucho después (1657), en la Descripción de San Lorenzo del Escorial de F. Francisco de Santos ${ }^{69}$.

Las Obras de Mengs proporcionan contextos de esta familia léxica, siendo los de plantado, adjetivo que 'se aplica a la figura que insiste perpendicularmente sobre uno o los dos pies $^{170}$, dos fragmentos donde se percibe claramente este matiz significativo:

En la inferior hay ventanas quasi redondas; y por eso Corregio fingió una especie de zócolo que gira alrededor como anexándose, y dexa lugar para que entre las ventanas quepan los Apóstoles que están puestos a uno y a dos; y no obstante que algunos caen sobre la misma línea de los ángulos, se hallan tan bien colocados y escorzados, que no ofenden nada la vista, y parecen plantados perpendicularmente sobre la cornisa (Obras de Mengs, p. 292).

La cabeza se debe inclinar hacia donde el brazo esté levantado, y volverse a la parte donde la mano esté más banzada. Si es una figura plantada, el tovillo interior del pie sobre quien se tiene ha de corresponder al hoyuelo de la garganta, como explicaré en otro lugar (Obras de Mengs, p. 376).

2.1.7.6. Otro magnífico caso de especialización semántica es el del sustantivo punzón, el cual desde su significado original 'instrumento de hierro o de otro material rematado en punta', evoluciona al de 'pequeña lámina de acero en cuya superficie está grabado en relieve el ojo de una letra o signo, y que se utiliza para la obtención de una matriz que sirve para fundir una letra, signo o viñeta ${ }^{171}$; tecnicismo del ámbito de la Imprenta incluido en Autoridades y del que las Obras de Mengs dan un ilustrativo testimonio:

En las partes donde había alguna más instrucción por causa de la comunicación con la Italia, como Augusta y Nurembérg, ciudades libres, florecía algo la Pintura; y aún más el Gravado, con motivo del uso de gravar las armas, y de hacer los punzones para la Imprenta, recién inventada entonces con tanta utilidad de la literatura y del comercio (Obras de Mengs, p. 263).

2.1.7.7. Por último, mencionaremos las voces subido y subir en su uso terminológico propio de la Pintura. Así, subir un color se define como 'aumentar la intensidad de una tinta' ${ }^{72}$, lo que en las Obras de Mengs se explica del siguiente modo:

\footnotetext{
${ }^{69}$ V. Carducho (1633), F. de Santos (1657).

${ }^{70}$ J. L. Morales y Marín (1982).

${ }^{71}$ J. L. Morales y Marín (1982).

${ }^{72}$ M. Bazzi (1965), p. 333.
} 
Además de esto tenia Rafael otra máxima aún más errónea; pues ponía una luz igual sobre las ropas que de su naturaleza debían ser de color puro: esto es, hacía un vestido azul, como se ve, por exemplo, en el Apóstol que está sentado en la delantera del quadro de la Transfiguración, y le ponía luces del todo blancas; lo qual no es posible, siendo las sombras y las medias tintas tan fuertes como las hizo: y esto es lo que yo llamo subir los colores hasta cerca del blanco en las luces, y baxarlos hasta tocar el negro en las sombras en la delantera del quadro (Obras de Mengs, p. 102).

\subsection{Las voces del siglo XVIII en las Obras de Mengs}

El siglo XVIII es considerado en la diacronía del español como un momento de estabilización y sosiego, debido en gran medida a que todas las etapas anteriores de la lengua estuvieron marcadas por una notable evolución en los aspectos más profundos de lo idiomático. Quizás por esto, y por la brillantez del español áureo en todas las parcelas, además de la sensación de estabilidad que dan las pautas dictadas desde principios del siglo XVIII por la RAE, se ha considerado este un siglo poco interesante para la historia del español. Sin embargo, en los últimos tiempos numerosos investigadores han puesto de relieve la necesidad de atender a esta centuria, como a las otras, para tener una perspectiva más nítida y realista de la historia del español, superando tópicos y llenando vacíos ${ }^{73}$. Por otra parte, y no menos importante, esta nueva atención ha desembocado en una revisión de algunas de las fronteras cronológicas generalmente aceptadas como las propias del español moderno. Recientemente, y a partir de las precisiones de Álvarez de Miranda en relación al léxico de la Ilustración ${ }^{74}$, se ha propuesto una periodización que distingue como primer español moderno el que comenzaría hacia 1675 y acabaría en $1825^{75}$. En este sentido, en nuestro trabajo, hemos atendido en puntuales casos a voces documentadas a fines del siglo XVII entendiendo que su desarrollo y afianzamiento en el idioma es propiamente dieciochesco.

Además, si bien es innegable la acelerada evolución sufrida en lo fonético que supera el idioma tras los grandes cambios acaecidos en los Siglos de Oro, el plano léxico, el del ensanchamiento de las fronteras del idioma, el del acercamiento de la lengua a la historia social y científica, sigue en ebullición. Así lo confirman todos los estudios que prestan atención a la entrada del vocabulario científico y técnico y al denominado léxico de la Ilustración, que es espejo de la inauguración de una nueva época ${ }^{76}$. Paradigmática de este cambio es, desde fines del siglo XVII, la adopción de valores propios de un nuevo clima ideológico en voces ya existentes. En nuestro texto, podemos constatar alguna novedad semántica citada por Álvarez

\footnotetext{
${ }^{73} \mathrm{M}^{\mathrm{a}} \mathrm{T}$. Godoy (2012).

${ }^{74}$ P. Álvarez de Miranda (1992).

75 Á. S. Octavio de Toledo (2008).

${ }^{76}$ G. Clavería (2012).
} 
de Miranda ${ }^{77}$, como el verbo ilustrar, neologismo áureo cuyo sentido en nuestro texto, mostrado por el adjetivo deverbal ilustrado, apunta ya a una realidad nueva: "es menester la razón ilustrada"78, "en tiempos muy ilustrados"79.

En lo que sigue se estudiarán sintéticamente las voces pertenecientes a esta centuria.

2.2.1. Anacronismo es ejemplo de consolidación léxica en el español del siglo XVIII, en el marco de mutua influencia de las lenguas europeas modernas. Helenismo que en italiano se documenta ya en el siglo $\mathrm{XVI}^{80}$, comienza a aparecer en textos de principios del siglo XVII en inglés $(1626)^{81}$ y francés $(1625)^{82}$. En español lo encontramos en 1684, en los Discursos politicos, y morales en cartas apologeticas, de Gonzalo Navarro ${ }^{83}$. El término, que no se localiza en textos portugueses hasta $1712^{84}$, probablemente surge en nuestro idioma mediante lo que Álvarez de Miranda denomina "creación inducida", por la que se acuñan nuevas voces a partir de afijos derivativos y raíces tomadas en este caso del griego, pero que tienen un modelo en una o varias de las lenguas contemporáneas ${ }^{85}$.

En español, la voz solo empieza a ser frecuente en el siglo XVIII; respaldada por su inclusión en Autoridades, dos de los primeros autores que la emplean son Feijoo (1734) y Mayans y Siscar (1737), según los datos consignados en CORDE.

El contexto en que incluye esta voz Azara es el siguiente:

Este quadro, pues, fue hecho, como otros muchos, a devoción de alguno que quiso varios Santos juntos sin que formen una historia o asunto particular. No por esto se deben acusar de anacronismo los Pintores ni los Aficionados; porque tales Pinturas se supone que representan especie de visiones espirituales, en que místicamente se juntan varios Santos, con quienes el que manda hacer la obra tiene particular devoción (Obras de Mengs, p. 290).

2.2.2. Bambochada 'cuadro o pintura que representa borracheras o banquetes ridículos', procede del it. bambocciata, y este de bamboccio 'bamboche'. El italiano generaliza la voz durante el siglo XVII ${ }^{86}$ y el francés la conoce desde $1680^{87}$.

77 Vid. P. Álvarez de Miranda (1992), pp. 183-192 y P. Álvarez de Miranda (2004), p. 1043.

${ }^{78}$ Obras de Mengs, p. XXXIV.

${ }^{79}$ Obras de Mengs, p. 244.

${ }^{80}$ A. Prati (1970) lo encuentra en la Traducción del Tácito de Bernardo Davanzati.

${ }^{81}$ DCECH s.v. crónica, n. 1.

${ }^{82}$ O. Bloch y W. v Wartburg (1968) y CNRTL (2012) s.v. anachronisme.

${ }^{83}$ G. Navarro y J. Navarro Castellanos (1684), p. 194.

${ }^{84}$ J. P. Machado (1967).

${ }^{85}$ Malkiel describió este fenómeno como una "cadena panrománica" de influencia mutua, vid. Y. Malkiel (1957), P. Álvarez de Miranda (2004), pp. 1041-1042.

${ }^{86}$ C. Battisti y G. Alessio (1975) y A. Nocentini (2010), s.v. bamboccio. 
El Diccionario de Autoridades no recoge bambochada, pero sí bamboche como término de la Pintura: 'Especie de país en que se pintan borracheras o banquetes flamencos'. Por otra parte, esta voz no se recoge en CORDE hasta 1962, lo que nos deja para su primera documentación la que consignan los diccionarios especializados, el primero de que tenemos constancia, el de Palomino y Velasco $(1715)^{88}$. En todo caso, su novedad en nuestra lengua resulta evidente para Azara que incluso ofrece la definición del neologismo:

Por Bambochada se entiende un asunto bajo, plebeyo y ridículo. Viene este nombre de un cierto Pedro Laar, Pintor Flamenco, feo y corcobado, que en el siglo antecedente pintaba estas cosas en Roma, donde le pusieron por apodo el Bambocho. Es un género de Pintura despreciable, y que pide poquísimo talento y corrección. La escuela Flamenca ha sobresalido en él, creyendo que la fiel imitación de qualquiera cosa hace todo el mérito de la Pintura; y así han tomado sin discreción una parte por el todo del Arte. Palomino en su elogiadora é indecisa explicación llama a las bambochadas, baratijas y bodegoncillos (Obras de Mengs, p. XXX, n. 1).

2.2.3. Caricatura, 'figura, dibujo o descripción en que se ridiculiza a alguna persona, deformando o exagerando sus facciones o su aspecto', encuentra una de sus primeras documentaciones en español en nuestro texto, donde se es muy consciente de su estatus extranjero, que Azara deja patente en los comentarios sobre su sentido, relacionándolo con otro italianismo, este semántico: cargado:

No hay voz en nuestra lengua que explique lo que es en Pintura cargado y caricatura, y por eso uso la voz Italiana. Cargar una figura es señalar más allá de la verdad las partes imperfectas y defectuosas: como por exemplo, si un hombre tiene la nariz un poco grande, hacérsela grandísima, y monstruosa. De ello resulta una caricatura, esto es, una cosa ridícula. Un contorno, o una parte qualquiera que debe señalarse suavemente, si se hace con más fuerza de la necesaria, se llama un contorno cargado (Obras de Mengs, p. 33, n. 1).

Respecto a su datación, hemos encontrado esta voz en CORDE en el Viaje a Italia de F. de Moratín (1793-1797); su introducción en los diccionarios académicos no ocurre hasta la sexta edición del DRAE $(1822)^{89}$, por lo que se podría considerar el texto de Mengs-Azara una de sus primeras apariciones en nuestra lengua.

\footnotetext{
${ }^{87}$ DCECH s.v. bamboche.

${ }^{88}$ Vid. L. Nieto y M. Alvar Ezquerra (2007), s.v.

${ }^{89} \mathrm{Vid}$. NTLLE.
} 
2.2.4. Colosal, derivada de coloso (del lat. COLŎSSUS y éste del griego

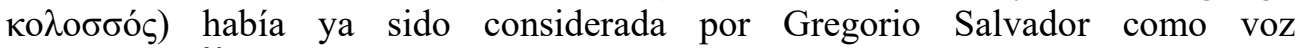
dieciochesca $^{90}$ :

En aquel tiempo, pues, se combinó que los mayores talentos fuesen empleados en obras las más vastas: y esto sirvió mucho para perfeccionar las Artes. Miguel Ángel fue escogido para hacer una Estatua en mármol de veinte y dos palmos y medio, la primera colosal que han emprendido los Modernos (Obras de Mengs, $\mathrm{p}$. 258).

La documentación de CORDE y la búsqueda en otras fuentes confirma aquella consideración de Gregorio Salvador, pues no hallamos ejemplos de la voz anteriores a este de 1754, incluido en la Historia general sacro-profana del Padre Delgado $^{91}$ :

Frontero de la cabecera de Catbalogan, en Sámar, se ven frecuentemente estos enormes y colosales peces. Navegando por allí en una embarcación bien pequeña, en la que apenas cabíamos cinco personas, ví dos que sacaron las cabezas bien cerca, y arrojaron tanta agua por alto que parecía un recio aguacero.

Existe, en este caso, la posibilidad de una influencia galicista, ya que, como bien señala Coromines ${ }^{92}$, la voz existe en francés desde fines del siglo $\mathrm{XVI}^{93}$ y de esa lengua parece haberse extendido a otras lenguas europeas modernas en el siglo $\mathrm{XVIII}^{94}$.

2.2.5. Corpúsculo, latinismo introducido por el historiador y poeta americano Carlos de Sigüenza y Góngora a fines del siglo XVII (1690), se documenta también en los textos de Torres Villarroel y Feijoo, en los que su sentido es el recogido por Terreros: 'átomo, pequeña parte de un cuerpo', donde evidentemente no se entiende todavía el término átomo con el valor científico que tuvo posteriormente ${ }^{95}$, pero que a nosotros nos interesa por la conexión con la definición de átomo que da Covarrubias: 'Se suelen llamar por su pequeñéz las motícas que andan por el áire tan imperceptibles que solo las vemos al rayo de Sol quando entra por los resquicios

\footnotetext{
${ }^{90}$ G. Salvador (1973), p. 26.

91 J. J. Delgado (1892).

92 J. Coromines (1980-91), s.v. colós y DCECH s.v. coloso.

${ }^{93}$ Así lo afirman los diccionarios etimológicos franceses consultados, vid. O. Bloch y W. v Wartburg (1968) y CNRTL (2012), s.v. colosse.

${ }^{94}$ Como el italiano, según apuntan C. Battisti y G. Alessi (1975) s.v. colossale, o el inglés, vid. D. Harper (2001-2014), s.v. colossal.

${ }^{95}$ Vid. el trabajo al respecto de C. Garriga (2008).
} 
de las ventánas, y las llaman átomos del Sol' y el sentido que se da a corpúsculo en las Obras de Mengs:

De la misma manera las cosas que se disminuyen por degradación, y que se pierden en el ayre, se pierden en el mismo tono, porque todos los corpúsculos del ayre interpuesto están teñidos del mismo color (Obras de Mengs, p. 369).

2.2.6 Directriz se documenta por vez primera en 1726, en el Teatro crítico universal de Feijoo ${ }^{96}$. A pesar de que los diccionarios, desde Terreros hasta bien entrado el siglo XIX, la recogen únicamente como término geométrico, en las Obras de Mengs se encuentra ya con el valor de la lengua común de 'instrucción o norma que ha de seguirse en la ejecución de algo':

Alguno opondrá quizá a esto, que la Arquitectura es hija de la necesidad; pero aquí se confundiría con el arte de fabricar que no es susceptible de Belleza, ni directriz de las demás Artes, como lo es la Arquitectura (Obras de Mengs, p. 189).

La voz directriz descendería del lat. medieval DIRECTRIX, femenino de DIRECTOR-ORIS 'guide, directeur ${ }^{197}$. En francés e italiano, la voz se documenta con los mismos significados que en español también a lo largo del siglo XVIII ${ }^{98}$.

2.2.7. Otras dos voces que no hemos podido documentar con anterioridad al

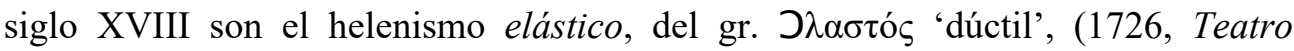
crítico universal de Feijoo) y su derivado elasticidad (1716, Hippocrates aclarado de Miguel Marcelino Boix y Moliner).

Este Reyno goza generalmente de un aire muy puro y elástico, que da mucho movimiento a los humores, e irrita fácilmente el sistema nervioso (Obras de Mengs, p. 183).

Elástico es adjetivo común a las otras lenguas europeas (ingl. elastic, fr. élastique, ital. elàstico, cat. elàstic, port. elastico) en las que se documenta desde el siglo XVII, $\mathrm{y}$ al que todas llegaron a partir del lat. científico ELASTICUS, der. del griego ${ }^{99}$.

\footnotetext{
96 Vid. PLE s.v.

${ }^{97}$ F. Gaffiot (1934), s.v.

${ }^{98}$ Vid. C. Battisti y G. Alessi (1975), s.v. direttrice y CNRTL (2012), s.v. directeur, trice.

99 Vid. J. P. Machado (1967) y D. Vieira (1878); A. Nocentini (2010); J. Coromines (198091); O. Bloch y W. v. Wartburg (1968) y CNRTL (2012); y D. Harper (2001-2014), s.v. elastic. A pesar de que G. Devoto (1989) documenta elastico en italiano ya en el s. XVI, tanto D. Harper (2001-2004) para el inglés, como J. P. Machado (1967) para el portugués, defienden la ascendencia francesa del término.
} 
Esta voz constituye un magnífico ejemplo de la cadena panrománica de influencia mutua de las lenguas modernas europeas ${ }^{100}$.

2.2.8. Elipse 'línea curva producida por un plano, que corta la superficie de un cono oblicuamente respecto de la base', es helenismo tomado a través de latín ELLIPSIS, común a las demás lenguas modernas ${ }^{101}$ en las que se documenta desde el siglo XVII. En el texto de Mengs-Azara aparece en binomio con el también tecnicismo oval:

La oval, o elipse, ya no es tan uniforme; y la triangular es la menos desagradable de todas las figuras regulares, porque los ángulos son de número desigual, y sus líneas no componen ninguna paralela (Obras de Mengs, p. 342).

Incluido en el Diccionario castellano y portugués de Bluteau $(1721)^{102}$, la primera documentación que podemos ofrecer se encuentra en el libro de Juan Bautista de Corachán, Arithmetica demonstrada theorico practica para lo mathematico y mercantil, de 1719.

2.2.9. En no pocas ocasiones, hallamos vocablos de excepcional interés. Un ejemplo, sin ser tecnicismo, que destaca por caracterizar los modos de la escritura de Azara, es la palabra espadachinar:

Para probar los defectos de la Estatua equestre de Marco Aurelio hace un volumen, donde lo que dice de verdadera crítica no pasa de tres renglones; lo demás se reduce a espadachinar a derecha y a izquierda contra todo el mundo: y lo peor es, mezclando sus querellas personales (Obras de Mengs, p. 174).

Espadachinar no se halla en ninguno de los diccionarios consultados ni está en los bancos de datos de la RAE (CORDE y CREA). Sí encontramos espadachinear 'ser amigo de pendencias y desafíos', en los diccionarios de Salvá (1846), Gaspar y Roig (1853) y Domínguez (1869). No obstante, el sentido de la voz que se deduce del fragmento de las Obras de Mengs es más bien el que ofrece Núñez de Taboada en su Diccionario Francés-español: "(fig.) 'Espadachinear: dícese de dos que disputan y contienden sobre materias de erudición' $[\ldots]^{\prime 103}$.

${ }^{100}$ Vid. supra, nota 86.

101 J. P. Machado (1967), A. Nocentini (2010), s.v. ellisse, J. Coromines (1980-91) s.v. ellipsi, O. Bloch y W. v. Wartburg (1968), s.v. ellipse y D. Harper (2001-2014), s.v. ellipse.

${ }^{102}$ L. Nieto y M. Alvar Ezquerra (2007), s.v.

${ }^{103}$ M. M. Núñez de Taboada (1820), s.v. escrimer. 
La forma espadachinar podría tener relación con el catalán espatatxinar ${ }^{104}$ que, según Moret i Coso, pertenece al acervo léxico del Aragón catalanófono ${ }^{105}$. Su uso en las Obras de Mengs podría confirmar cierta predilección dialectal ${ }^{106}$ de Azara que, en algún caso puntual, hemos querido ver, como en el uso del diminutivo de riso 'risa', risito, que podría ser debido a aragonesismo ${ }^{107}$ :

El colorido es verdadero y jugoso, de un Estilo medio entre el de Pedro Perugino, y Leonardo de Vinci: y en particular la cabeza de la Virgen se acerca mucho al Estilo y carácter de este último, especialmente en aquel risito de la boca y mexillas (Obras de Mengs, p. 293).

2.2.10. El galicismo gabinete, del fr. gabinet, toma en nuestro texto el sentido de 'local en que se exhibe una colección de objetos curiosos o destinados al estudio de una ciencia o arte'. Lo documentan Coromines y Pascual en 1705; nuestra búsqueda en CORDE adelanta esta datación en varias décadas, en un escrito de Calderón de la Barca de $1646^{108}$. Sin embargo, teniendo en cuenta que la voz no reaparece hasta 1724 en textos de Feijoo y Palomino Velasco, entre otros, podríamos considerar que gabinete en este sentido pertenecería al acervo léxico del siglo XVIII:

Hoy se hallan estos quadros en el mismo gavinete de la Princesa nuestra Señora donde están los sobredichos de Tiziano (Obras de Mengs, pp. 229-30).

2.2.11. Goticismo 'tendencia a lo gótico (arte desarrollado entre el siglo XII y el Renacimiento)' es por primera vez recogido en el Viaje a Italia de Fernández de Moratín (1793-97), por lo que nuestro texto podría ser una de las primeras documentaciones del término:

De la Arquitectura diré solamente, que apenas se dexó ver, quando desapareció hasta nuestros días, que la cultivan con buenas máximas algunos Profesores. Aun no se había desterrado enteramente el Goticismo (sin embargo de haberse hecho

\footnotetext{
${ }^{104}$ Espatatxinar 'desfer, esclafer' (A. M. Alcover y F. de B. Moll (1978), s.v.).

${ }^{105}$ H. Moret i Cosos (1996), p. 100.

${ }^{106}$ Hemos encontrado la voz en un par de textos literarios del siglo XIX: Don Pápis de Bobadilla (1829) de Rafael José de Crespo y la traducción de 1836-37 a cargo de Mor de Fuentes de Julia o La nueva Heloisa de Rousseau, ambos autores, como el nuestro, aragoneses, vid. R. J. Crespo (1829) y J. Mor de Fuentes (1836-37).

107 J. Pardo Asso (1938), s.v. riso.

${ }^{108}$ Evidentemente, nos referimos a la acepción más tardía de la voz, pues con la más general 'habitación donde se recibe a las personas de confianza' se documenta a lo largo de los siglos XVI-XVII (vid. E. Varela Merino (2009), s.v.).
} 
algunas buenas fabricas en Toledo, Granada, y otras partes) a tiempo que reynó Felipe II y se empezó el Escorial (Obras de Mengs, pp. 187-88).

2.2.12. Laca forma parte del léxico específico de la Pintura y las Artes en general con varias acepciones:

'Sustancia resinosa, translúcida, quebradiza y encarnada, que se forma en las ramas de varios árboles de la India con la exudación que producen las picaduras de unos insectos parecidos a la cochinilla, y los restos de estos mismos animales que mueren envueltos en el líquido que hacen fluir', 'Barniz duro y brillante hecho con esa sustancia resinosa y muy empleado por los chinos y japoneses', 'Por ext. objeto barnizado con laca', 'Color rojo que se saca de la cochinilla, de la raíz de la rubia o del Palo de Pernambuco', 'Sustancia aluminosa colorida que se emplea en pintura'109.

El sentido que recoge nuestro texto es el de 'color rojo que se saca de la cochinilla, de la raíz de la rubia o del Palo de Pernambuco':

Tenemos dos géneros de colores que nos ha dado la Naturaleza, es a saber, los obscuros y transparentes o diáfanos, y los claros; y también tenemos algunos obscuros que son opacos, como la laca, el azul, el negro de marfil, y otros semejantes; pero estos nunca pueden llegar a la opacidad que se hace con los transparentes (Obras de Mengs, p. 355)

Esta acepción, derivada de la primigenia 'sustancia resinosa de color rojizo', parece ser propia de fines del siglo XVIII: la primera vez que la rastreamos en CORDE es en la Relación histórica del viaje a los reinos de Perú y Chile de Hipólito Ruiz (1793-1801):

El Huanchaco, ó Piche, es un poco mayor que un gorrión, de color encarnado laca, por el pecho, y musgo por lo restante del cuerpo algunos se encuentran blancos, con el pecho encarnado: las hembras solamente tienen un corto viso encarnado por la garganta: dá vuelos cortos y baxa precipitadamente á tierra, como si fuera ave de rapiña: los machos aprenden con facilidad los canticos que se les enseña y varias otras propiedades.

2.2.13. Lapicero 'instrumento en que se pone el lápiz para servirse de él', der. de lápiz, es vocablo que nace en el siglo XVIII, cuya más temprana documentación encontramos en 1778 en el Epistolario de Jovellanos ${ }^{110}$.

\footnotetext{
109 J. L. Morales y Marín (1982) s.v.

${ }^{110}$ M. Davies (2002-), s.v.
} 
Destinado a 1a Pintura desde las mantillas, no le daban otros juguetes que las cosas relativas a esta profesión, como lapiceros, lápiz y papel; y antes de cumplir seis años ya le pusieron al estudio del diseño (Obras de Mengs, p. V).

2.2.14. Maquina, maquinista y maquinoso. En las Obras de Mengs, el término máquina se nos ofrece con un sentido terminológico que derivaría, por una extensión semántica, del significado ordinario 'artificio mecánico'. Lo recoge el Dizionario dei termini artistici ${ }^{111}$ con una acertada definición del tecnicismo nacido en el italiano, precisamente en el siglo XVIII:

Per estensione del significato ordinario de complesso ordigno meccanico, la voce $M$ [achina] fu assunta nel sec. XVIII per indicare una composizione pittorica di carattere scenografico e decorativo.

En nuestro texto, se percibe este valor, entre otros contextos, en el uso de "composición maquinosa" del siguiente pasaje:

Lo que tal vez no poseyeron los Antiguos con la perfección que los Modernos es la composición maquinosa, porque su principal estudio era la perfección y la qualidad de las cosas, y no la quantidad de ellas (Obras de Mengs, p. 255).

Aquí, maquinoso, adjetivo derivado de máquina, adquiere también los valores de tecnicismo de su base. La palabra, cuya primera documentación está en La Hispálica de Luis Belmonte Bermúdez (1600) según los datos proporcionados por CORDE, es utilizada por sor Juana Inés de la Cruz y está en la Historia de Guatemala de Francisco A. de Fuentes y Guzmán (1690), si bien no percibimos el matiz terminológico citado en estas autoridades.

De este modo, la voz maquina designaría una composición pictórica compleja en cuanto que compuesta por multitud de partes que, como las piezas de una máquina, deben producir un efecto de unicidad para formar un todo perfecto. Tal y como exponen Grassi y Pepe en el mencionado artículo: "Le M[acchine], intese in questo senzo, non potevano essere apprezzate dai critici neoclassici". Lo que comprobamos en el siguiente fragmento de las Obras de Mengs:

Algunos dirán que los Pintores de Máquinas, como Lanfranco y Berretino, no pueden sujetarse a una exacta verdad, trasportándolos el fuego de la composición fuera de los límites de la escrupulosa exactitud. Pero yo les responderé que no veo menos obligación de observar la verdad en una composición de cien figuras, que en una de diez: y así esta razón no puede escusar a ningún Pintor con las gentes de juicio; tanto más que yo hablo aquí de la invención, y no del Efecto,

${ }^{111}$ L. Grassi y M. Pepe (1994), s.v. 
que pertenece al Clarobscuro, en el qual convengo que Rafael no poseyó todo lo Ideal que se necesita; pero sin embargo, ningún otro Pintor ha hecho quadros mayores, ni más llenos de figuras. En ellos supo disponer excelentemente sus grupos; los enlazó bien entre sí: cada figura en particular es lo que debe ser; y todo según la más exacta verdad. ¿Después de esto qué escusa podrán hallar los Maquinistas para su manera? (Obras de Mengs, p. 114).

2.2.15. Monocromista y monocroma son voces enciclopédicas. Monocroma 'pintura de un solo color', como la describe Azara, remite al término monocrómata recogido por Terreros con la explicación: 'llaman en Pintura a la que es de un solo color'. Esta aclaración, sin embargo, es insuficiente si la comparamos con la que encontramos en otros lugares y que relacionan monocrómata con monocromato, como género pictórico, así como con monocromo y monocromista, voces documentadas en el texto de Mengs-Azara. Así, Carducho en 1663 explica:

Començaron después con un color, que llamaron Monocromato, invención de Cleofano Corintio; pero él, y otros obraron con tan poca luz del Arte, que admiró Eumano Ateniense, quando vieron que distinguió al varón de la muger, y puso variedad en otras cosas, [al margen: Zinón Cleneo.] a quien siguió, y perficionó Zenon Cleoneo, que halló los Escorços, que llamaron Catagraphes ${ }^{112}$.

Y, antes que él, usando el helenismo crudo, Céspedes (1605) había escrito:

La pintura llamada acerca de los antiguos Monocromatón i la que llamaron Linearis, a mi parecer poco diferentte la una de la otra, ideo et quos pingerent adscribere institutum, no se a de entender lo que algunos dizen por donaire, este es ombre i este cavallo ${ }^{113}$.

Mejor lo expresa ya en 1563, Manuel Denis en su Traducción "De la pintura antigua" de Francisco de Holanda, en lo que parece ser la primera documentación del término aún extranjero:

Los egipcios (según escribe Cayo Plinio) afirman ser esta arte hallada de ellos, muchos años antes que viniese a Grecia; mas, es manifiesto que ellos predican lo que es falso. Los griegos dicen, que fué hallada de los sciciones, algunos; y otros, que de los corintos. Pero, todos concordan, que fué hallada de la sombra de el Hombre, rodeada con una raya; y así fué la primer pintura que el que esto escribió comenzó a hacer acaso siendo muy niño, cercando con un perfil la sombra de su mano de la pared. Mas la segunda fué de una sola color e fué

112 V. Carducho (1633), f. 27r.

${ }^{113}$ P. de Céspedes (1605), p. 277. 
llamada monocromaton, la cual dura hasta el presente tiempo (Traducción "De la pintura antigua" de Francisco de Holanda, p. 24) ${ }^{114}$.

El texto de Mengs-Azara usando el término monocroma y su derivado monocromista se refiere a la misma realidad:

Es verisímil que este estado de infancia de la Pintura (si es que le hubo) durase poco tiempo en Grecia. Plinio, que compiló todos los Autores que escribieron antes de él, no obstante que solo por incidencia trata de los colores, da una idea de lo que debieron ser los coloristas anteriores a los Monocromistas; y como yo supongo que principalmente habla de los Griegos, se puede congeturar que abandonaron presto aquella primitiva manera, y comenzaron a usar algo de clarobscuro, y a hacer las Monocromas... (Obras de Mengs, p. 253).

Por lo tanto, en este caso, no remite la voz monocroma a la pintura de un solo color en general, sino a la corriente pictórica a la que se alude en los ejemplos anteriores y de la que, naturalmente, descendería monocromista para referirse a los autores que cultivaron el estilo antiguo del Monocromo y cuya definición y origen se expresa en la siguiente cita de la Teoría e historia de las Bellas Artes (1859) de Josep Manjarrés:

Dos clases de dibujo usaron pues las escuelas griegas empleando el estilo unas veces y otras el pincel con un solo color. Las obras ejecutadas por este método se llamaron monocromata, así como los trazados con el estilo se llamaron monogramma ${ }^{115}$.

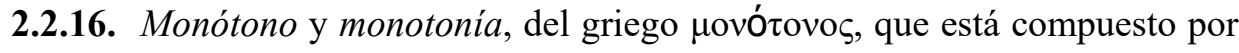
el elemento - $\tau$ ovos, el cual produce "vocablos en el sentido de sonido musical o lingüístico" ${ }^{116}$, hacen aparición en español a lo largo del siglo XVIII, tanto en su acepción etimológica 'uniformidad en el tono en que se habla o canta', como en el sentido mucho más frecuente y siempre peyorativo 'excesiva uniformidad', 'lo que resulta tedioso'. En el texto de Mengs-Azara, los contextos muestran levemente el movimiento semántico desde el sentido etimológico:

Esto se acomoda únicamente a los muchachos, en quienes hay poca fuerza y variedad; y por eso los de Dominiquino tienen este mérito. En las otras figuras es fría y monótono. Muchas de sus ideas son baxas y ordinarias; y con todo eso las repetía demasiado, y tenía asuntos favoritos, que repetía continuamente (Obras de Mengs , p. 113).

\footnotetext{
114 Apud CORDE.

115 J. Manjarrés (1859), p. 329.

${ }^{116}$ D. Pharies (2002), p. 492.
} 
Sus quadros suelen tener una monotonía de color desagradable; y por eso no gustan a primera vista, y necesitan de la reflexión (Obras de Mengs, p. XXXVII).

Con respecto a la primera datación de estas voces en español, nuestra búsqueda adelanta mínimamente la ofrecida por el DCECH (1765) a 1745, en el Diccionario trilingüe: Castellano, Bascuence y Latín de Manuel de Larramendi, en cuyo Prólogo podemos leer:

Pero los que tal dixeren, no saben de musica, no como de la variedad de tonos resulta una harmonia consonantissima, y agradable, y llamaran también confusion aborrecible à lo que saliere de una xacara monotona, y molestissima de una hora ${ }^{117}$.

Esta primera documentación, así como la siguiente, de 1753, en la traducción que el padre Terreros hace del Espectáculo de la naturaleza de Noël Antoine Pluche, es ejemplo del uso etimológico de la voz; sin embargo, como comprobamos en CORDE, el sentido predilecto en el uso, sobre todo a partir de fines del siglo XVIII, es el de 'uniformidad tediosa', 'tedioso' ${ }^{118}$.

Monotonía y monótono son voces comunes a los demás idiomas europeos que en francés e italiano se documentan en el siglo XVII, a principios del XVIII en inglés y más tardíamente en catalán y portugués ${ }^{119}$.

2.2.17. Derivado de mosaico con el sufijo culto -ista ${ }^{120}$, el sustantivo mosaiquista 'fabricante de mosaicos' no aparece en CORDE ni se recoge en los diccionarios académicos hasta 1989. Las primeras documentaciones de esta voz que

\footnotetext{
${ }^{117}$ M. de Larramendi (1745), p. XXIV.

${ }^{118}$ Esta base de datos permite comprobar el impresionante incremento de las ocurrencias en el siglo siguiente. Así, frente a los 9 casos del adjetivo y 7 del sustantivo del siglo XVIII, tenemos 510 ocurrencias de monótono y 249 de monotonía en el siglo siguiente. No podemos dejar de relacionar estos datos con el problema filosófico del aburrimiento, el cual fue abordado por el francés Pascal (1623-1662): "Nada es tan insoportable para el hombre como estar en pleno reposo" y que a mediados del siglo XIX ya se consideraba el Mal du siècle.

${ }^{119} \mathrm{La}$ documentación más antigua de que tenemos constancia sería la del ital. monotonia que, según A. Prati (1970), s.v. monòtono, está en el Tratado de música de G. Doni (15941647); el fr. monotonie se documenta en 1671 (O. Bloch y W. v. Wartburg, 1968, s.v. monotone); en catalán, J. Coromines (1980-91) localiza el término en el Diccionari de Pere Laberna (1839); en portugués no hay documentaciones hasta 1873, según los diccionarios consultados, vid. J. P. Machado (1967).

${ }^{120}$ Sufijo formante de sustantivos denominales que designan profesión (D. Pharies, 2002, p. $358)$.
} 
hemos rastreado son de fines del siglo XVIII y principios del XIX en el Epistolario de Azara, así como en las Obras de Mengs y en las Observaciones de Isidoro Bosarte $(1791)^{121}$. Se podría considerar en su formación la influencia del italiano mosaicista cuyo uso se recoge en el siglo XVIII ${ }^{122}$.

El gran comercio de la Italia con la Grecia, y con otras partes del mundo, introduxo la opulencia: y queriendo los Italianos edificar Iglesias, y adornadas con Imágenes, vinieron aquellos miserables Pintores y Mosayquistas que entonces había a hacer aquello poco que sabían; y con este motivo aprendieron algunos Venecianos, Boloñeses, Toscanos y Romanos a trabajar con la misma rusticidad que veían en sus maestros (Obras de Mengs, p. 256).

2.2.18. Octangular 'octagonal [octogonal] ${ }^{123}$ es latinismo raro incluso en los textos especializados:

En Roma hubo otro quadro octangular, donde Corregio repitió las dos figuras de la Ciencia y de la Virtud que contiene el quadro penúltimo que he descrito. En medio pintó un escudo de armas con algunas estrellas, y despues hizo encima una especie de campo; pero no dexaba de conocerse lo que había pintado antes (Obras de Mengs, p. 286).

La primera ocurrencia de esta palabra en CORDE es de 1834; no obstante, la búsqueda en otras fuentes adelanta esa fecha en un artículo de la Gaceta de Madrid de 4 de octubre de 1791:

En la misma noche se trabajó y amaneció el siguiente día en la plaza un prospecto de bastidores pintados que bien armado en figura octangular manifestó en sus ochavas quatro fuentes $[\ldots]^{124}$.

2.2.19. Omisible es neolatinismo que ve la luz, como los vocablos anteriores, en el siglo XVIII.

Esto no lo decía porque gustase de la negligencia; sino para dar a entender que sabía omitir lo que era omisible, y que si los demás Pintores tenían algunas partes de la perfección, él poseía la unión de todas ellas (Obras de Mengs, p. 139).

\footnotetext{
${ }^{121}$ I. Bosarte (1791), p. 63; J. N. de Azara (1784-1804), p. 60 (en carta de 1789). Vid. también Real Academia de Bellas Artes de San Fernando (1802), p. 150.

122 A. Nocentini (2010), s.v. mosaico.

${ }^{123}$ A. Pagés (1925), s.v.

124 "Relación de las fiestas celebradas por la ciudad de San Felipe y Santiago de Montevideo en la proclamación del Señor Rey D. Carlos IV", Gaceta de Madrid n 79 (Anónimo, 1791, p. 731).
} 
La primera datación de esta palabra de que tenemos constancia corresponde a los Rudimentos de táctica naval (1776) de Mazarredo Salazar ${ }^{125}$. La voz, que no aparece en CORDE, se encuentra en una veintena de tratados del siglo XIX. De su suerte nos hablan los datos del siglo XX en el que se comprueba su arraigo en el español culto con más de trescientas apariciones en libros de la biblioteca digital Google Books; se incluye en el diccionario académico desde 1970.

2.2.20. En el caso de paleta, diminutivo de pala mediante el sufijo -eta (de origen catalán o francés), la primera ocurrencia de la voz en 1374-91 no corresponde a la acepción propia de la Pintura: 'tabla pequeña sin mango y con un agujero a un extremo de ella, por donde para sostenerla mete el pintor el dedo pulgar izquierdo y en el cual tiene ordenados los colores' ${ }^{126}$, la cual no se documenta hasta 1705 en el Universo abreviado de Pomey ${ }^{127}$ y, después, en El Parnaso español pintoresco laureado de Palomino y Velasco en 1724. En nuestro texto se emplea con frecuencia:

De Corregio dicen que la vista entra dentro de sus sombras, y que se puede poner la mano entre un objeto y otro; lo que nada tiene que ver con el Colorido: porque esto se puede hacer en un Diseño; y lo otro en la paleta de los colores (Obras de Mengs, p. 133).

2.2.21. El término pátina se documenta en el siguiente pasaje de las Obras de Mengs:

Volviendo a la Galería de Saxonia, hay también en ella un quadro de la Virgen de media figura con el Niño durmiendo en los brazos, el qual fue gravado por el célebre Eidelink creyéndole de Corregio; pero se sabe de cierto que hizo esta obra Sebastián Rici, Veneciano, con designio de hacerla pasar por de Corregío, pretendiendo imitar su manera, y dándola cierto rancio o patina a fin de que pareciese antigua. Pero solo con examinar cuidadosamente la estampa, se descubre la impostura, pues en vez de gracia no hay más que afectación, y en el clarobscuro falsedad (Obras de Mengs, p. 302).

En este contexto podemos observar que el significado coincide con el recogido por Morales y Marín: 'Tono sentado y suave que da el tiempo a las pinturas al óleo y a las construcciones ${ }^{\prime 28}$. Las documentaciones de la voz, todas posteriores a la de

\footnotetext{
125 J. de Mazarredo (1776), pp. 3 y 50.

126 J. L. Morales y Marín (1982); M. Bazzi (1965) s.v.

${ }^{127}$ L. Nieto y M. Alvar Ezquerra (2007), s.v.

128 J. L. Morales y Marín (1982), s.v. 2.
} 
nuestro texto, son de fechas tan tardías como 1872 en CORDE, 1866 en el Corpus del Español y $1841^{129}$, en la Biblioteca digital Google Books.

Respecto a su etimología, hemos decidido incluir la voz entre los préstamos del italiano (a pesar de lo indicado por Coromines y Pascual ${ }^{130}$ ) teniendo en cuenta la información tomada de Nocentini, que documenta el italiano patina 'velatura che si forma col tempo sugli oggetti' en 1696 y añade que "dall'italiano vengono il fr. patine e lo sp. pátina"131.

2.2.22. Pintoresco, adjetivo que se aplica 'a lo que está pintado con buen manejo', adaptación del italiano pittoresco, se documenta en CORDE en el Triunfo parténico del erudito mexicano Sigüenza y Gongora de 1683, fecha que adelanta la datación ofrecida por Coromines y Pascual, 1708, en unos pocos años. Con su habitual perspicacia en lo lingüístico, Azara escribe la palabra en cursiva, lo que podría indicar que la novedad del término se percibe aún a fines del siglo XVIII:

En esto consiste el artificio del Pintor, y con el hace pintoresco qualquier objeto de la Naturaleza, dándole una disposición capaz de dispertar particular sensación en el ánimo de los que le miran (Obras de Mengs, p. 204).

2.2.23. Otra rara avis léxica, es piramidar, que habremos de poner en relación con el adjetivo piramidado 'que presenta forma de pirámide', el cual hemos logrado documentar desde 1786 en textos de índole muy especializada. Creemos que piramidado podría ser un italianismo ${ }^{132}$. Y no es imposible que Azara, acostumbrado al uso del adjetivo, considerase el uso de un verbo del que podría ser este su participio. En cualquier caso, a Azara no se le escapa la rareza del neologismo e incluye, en nota, una definición del nuevo infinitivo:

Piramidar los grupos es hacer que el conjunto de los objetos forme figura de pirámide: esto es, que tenga más basa que punta. En qualquiera otra forma que se dispongan, sea recta o circular, hará mal efecto (Obras de Mengs, p. 236, n. 1)

2.2.24. Plástica 'arte de plasmar, o formar cosas de barro, yeso, etc.' es helenismo que ha penetrado en el español por vía latina:

\footnotetext{
${ }^{129}$ M. Palouze (1841).

${ }^{130}$ Vid. DCECH s.v. paila.

${ }^{131}$ A. Nocentini (2010), s.v.

${ }^{132}$ Con este sentido está piramidato en Academia della Crusca (1724). También en catalán existe la palabra, cuya documentación está en el Diccionari Aguiló (A. M. Alcover y F. B. de Moll (1964-69), s.v.).
} 
Con que si el modelar enseñó a Bonarota aquel Estilo que es propio suyo, no será estraño que la inteligencia de los bellos contornos, y el Estilo grandioso de Corregio vengan del mismo origen, esto es, del estudio del relieve, y de modelar las figuras: y así sabemos que exercitó la Plástica (Obras de Mengs, p. 312).

Las documentaciones en CORDE son numerosas a partir de 1742 (de nuevo regalo de Feijoo en sus Cartas eruditas y curiosas). Por nuestra parte, la primera datación a la que hemos tenido acceso está en la Filosofía Moral de Emanuel Tesauro (1723):

Enseñaron la Arquitectura las Abejas; la Musica los Ruiseñores, las Escultoras las ossas, la Plastica los escarabajos, la Nautica los Cisnes, el flechar el Puerco espin $[\ldots]^{133}$

2.2.25. La voz prisma es término geométrico también tomado del griego por medio del latín, cuyo significado es el de 'cuerpo limitado por dos polígonos planos, paralelos e iguales que se llaman bases, y por tantos paralelogramos cuantos lados tenga cada base. Si estas son triángulos, el prisma se llama triangular; si pentágonos, pentagonal, etc.'. El sentido de esta voz que se recoge en el texto de Mengs-Azara es el correspondiente al del prisma triangular que, cuando es de cristal, se usa para producir la reflexión, la refracción y la descomposición de la luz ${ }^{134}$ o como explicaba más sencillamente Terreros: "el prisma triangular hace ver varios colores":

Para hallar Harmonía en los colores sería menester determinar, dar un numero a cada color; lo que seria dificultosísimo, y quizás imposible: porque supuesto que se quisiesen numerar los grados de los ángulos de refracción que el rayo de la luz forma en el prisma, vendría a ser un estudio dilatadísimo, y al mismo tiempo ageno de la Pintura, e inútil a los Pintores (Obras de Mengs, p. 364).

Este tecnicismo empieza a aparecer en textos especializados a partir de finales del siglo XVII, el primero que se documenta en CORDE es de 1675 (Fábrica y usos de varios instrumentos matemáticos de José Zaragoza ${ }^{135}$ ); la búsqueda ampliada en Google Books confirma este dato, pues solo hemos localizado la voz en un texto anterior del mismo autor, la Geometria especvlativa, y pratica de los planos, y solidos, publicado en 1671.

Como en casos anteriores, una voz entrada al inicio del periodo que se ha denominado primer español moderno va a arraigar en la lengua a lo largo de ese

\footnotetext{
${ }^{133}$ E. Tesauro (1723), p. 285.

${ }^{134}$ DRAE s.v.

${ }^{135}$ Una documentación anterior registrada en CORDE es una errata evidente: "Al Marqués de Priego le dan mucha prisma [*por prisa] vaya á Roma á dar [...]" (Jerónimo de Barrionuevo, 1654-58).
} 
periodo acrecentándose su frecuencia a lo largo de este siglo para mostrar su afianzamiento en el siguiente ${ }^{136}$.

2.2.26. Retratista 'persona que hace retratos' es otro derivado denominal en -ista (que añade el valor de oficio) del que, como en el caso de tallista, no encontramos ejemplos hasta el siglo XVIII.

Los Aficionados, viendo tales cosas bien imitadas, se acostumbran a aquel gusto de Pintura: y para complacerlos es necesario que el Retratista ponga en sus quadros un cierto brillo picante, y que los haga ricos de variedad, a fin de que los Retratados se vean como van regularmente. En Roma, donde domina el Gusto del Antiguo, se hace poco caso de esta variedad, y se procura executar las cosas con la mayor simplicidad posible (Obras de Mengs, pp. 131-32).

El término retratista tiene su primera documentación en El Parnaso español pintoresco laureado (1724) del maestro Palomino y Velasco. El DRAE lo incluye en su cuarta edición (la de 1803) ${ }^{137}$. No podemos decir si este derivado es, como su base, italianismo, si bien su documentación en esa lengua es anterior a la de la nuestra (de mitad del s. XVII), según registra Nocentini ${ }^{138}$.

2.2.27. El vocablo rigorismo 'exceso de severidad, principalmente en materias morales o disciplinarias', der. del latinismo rigor más sufijo -ismo, sería también neologismo del siglo XVIII, cuya datación no es, según nuestros datos, anterior a 1745, en el tomo II de las Cartas eruditas y curiosas de F. Benito Jerónimo de Feijoo, autor que, como se ha visto, dio entrada a tantas voces en nuestra lengua:

Mas quando fuesse cierto que los censores huviessen de explicarse por arancel, ¿por dónde serían comprehendidos en esse rigorismo los de las obras de este sabio? (Cartas eruditas y curiosas, t. II, p. XXII) ${ }^{139}$.

En nuestro texto, adopta el mismo sentido:

Aquel Caballero las tuvo en mucha estimación mientras vivió; pero sus herederos las vendieron, comprando las Estatuas Felipe V Rey de España, y las Pinturas el Duque de Orleáns Regente de Francia: del qual vinieron a manos del padre del actual Duque, que por principios de rigorismo las hizo despedazar en su presencia, para que no le engañasen, y al mismo tiempo hizo quemar la cabeza

\footnotetext{
${ }^{136}$ Las consultas en CORDE muestran que, frente a los 15 casos de prisma de entre 1675 y 1825, el periodo comprendido entre 1826 y 1899 ofrece 296.

137 Vid. NTLLE.

${ }^{138}$ A. Nocentini (2010), s.v. ritratto.

${ }^{139}$ Apud CORDE.
} 
de la Io, (otro quadro de Corregio) porque le parecía la más expresiva (Obras de Mengs, p. 282).

Rigorismo existe en italiano, catalán y portugués ${ }^{140}$, en cuyas lenguas se documenta también en el siglo XVIII, según Nocentini ${ }^{141}$, procedente del francés, donde la voz se existe desde el s. XVII ${ }^{142}$.

2.2.28 Secatura 'insulsez', del it. seccatura der. de seccare 'fastidiar'; según Terreros, fue voz especialmente usada entre los militares.

Parece que Corregio consideraba todas las formas de la Naturaleza, que no están alteradas por el artificio, como si fuesen compuestas de líneas curvas, cóncavas o convexas, variando solamente en su magnitud y proporción; por lo que huía de todo lo que era ángulo, y por consiguiente de las menudencias y secaturas en que ordinariamente caían los Pintores de las Escuelas anteriores (Obras de Mengs, p. $311)$.

De entre las pocas documentaciones que CORDE ofrece de esta voz, la primera es de 1764 en La bella madre de Ramón de la Cruz, seguida ya de las aparecidas en las Cartas de Azara al ministro Roda de 1768.

2.2.29. El compuesto semidiáfano se incluye, desde 1846 hasta 1918 , en algunos de los diccionarios compilados en el NTLLE con la definición: 'lo que no es perfectamente diáfano' ${ }^{143}$. No hemos localizado ejemplos de esta voz en español anteriores al de nuestro texto, donde se es más concreto en la explicación del término de lo que son los diccionarios:

Lo mismo sucede en la Pintura, pues quando un color claro se pone sutilmente sobre otro obscuro, le vuelve pardo y el color obscuro puesto sobre el claro, aumenta el brillante de este: por cuyas razones un cuerpo semidiáfano nunca parece de color puro en la parte iluminada pero sí en aquella donde los rayos de la luz penetran dicho cuerpo, sin dexar la superficie iluminada (Obras de Mengs, p. 356).

\footnotetext{
140 J. P. Machado (1967), s.v., J. Coromines (1980-91), A. M. Alcover y F. de B. Moll (1978), s.v. rigorisme y A. Nocentini (2010), s.v. rigòre.

${ }^{141}$ A. Nocentini (2010).

${ }^{142}$ O. Bloch y W. v Wartburg (1968), s.v. rigueur, dan como primera datación el año 1696.

${ }^{143}$ V. Salvá (1846), J. Gaspar y J. Roig (1855), R. J. Domínguez (1869), E. Zerolo (1895), J. Alemany y Bolufer (1917) y M. Rodríguez Navas (1918).
} 
2.2.30. El término tallista 'persona que hace obras de talla', derivado de talla, hace referencia a un oficio que en castellano se denominó tradicionalmente entallador ${ }^{144}$.

Los Profesores de las otras Artes, y más que ellos los Tallistas, se apoderaron de lo poco que se ofreció desde entonces, que eran ornatos de Iglesias: y esto les fue muy fácil, porque en lo general de la Nación continuaron las cabezas en pensar que lo grande y lo bello consiste en lo rico; y ellos hacían las cosas ricas en apariencia (Obras de Mengs, p. 188).

La voz, que se recoge ya en Autoridades, será frecuente a partir de 1742, según datos extraídos de CORDE. La documentamos, además, en un par de libros de principios del siglo XVIII, el primero de ellos de Francisco Laguno (1718):

[...] a lo menos el Evangelio no habla palabra de Escultores, Tallistas, Pintores, Doradores, ni otros Artifices que pagasse para aderezarle la casa $[\ldots]^{145}$

2.2.31. El adjetivo tendinoso 'que tiene tendones o se compone de ellos', der. de tendón con el sufijo -oso, empleado en español, como lo hizo su étimo latino, para sugerir abundancia ${ }^{146}$, es término propio de la Anatomía, lenguaje específico, como se ha comprobado desde la entrada de latinismos y helenismos de la Edad Media, frecuente en los textos artísticos para la descripción del detalle pictórico o escultórico de los cuerpos.

Estas intersecciones se forman de varias maneras. Las hay en los miembros que se ven enteramente, quando la obliquidad de un músculo tiene su origen en la parte que no se ve; y las hay en los escorzados, a causa de que muchas veces un músculo se interrumpe porque la parte carnosa cubre la cóncava que le liga con la tendinosa [...] (Obras de Mengs, p. 343).

La primera vez que se registra la voz, según los datos de CORDE, es en un texto argentino de 1775 de Manuel Manchón; sin embargo, una búsqueda ampliada muestra la existencia de la voz en textos médicos de principios del s. XVIII y al menos uno de fines del XVII (1694), el Compendio cirurgico vtil y prouechoso a sus professores de Diego Antonio de Robledo:

144 A. de Nebrija (1495) traduce entallador como 'exculptor-oris' y con este sentido usa la palabra en numerosas ocasiones Alfonso X en la General Estoria y el Libro de las formas y las ymágines, entre otras documentaciones halladas en CORDE.

${ }^{145}$ F. Laguno (1718), p. 33.

146 D. Pharies (2002), p. 451. 
[...] y sale dicho alime $<$ n $>$ to por la cintura del perihostio, forma vn nudo de substa $<\mathrm{n}>$ cia hosea sobre el huesso, nerviosa sobre el nervio, y tendinosa sobre el tendo $<\mathrm{n}>\& \mathrm{c}^{147}$.

\section{Conclusiones}

Acabamos esta caracterización lexicológica de las Obras de Mengs señalando algunas consideraciones relevantes:

3.1 En primer lugar, se constata el oficio de Azara en la labor de traductor. Notamos su gran conciencia lingüística en la continua introducción de definiciones, explicaciones y reflexiones metalingüísticas que tienen como objeto clarificar al máximo el uso de voces especializadas o extranjeras. El afán de claridad del aragonés le hace usar no pocas veces analogías, reformulaciones o paráfrasis tras la inclusión de algún tecnicismo: "La cúpula no tiene linterna, esto es, abertura en el centro, ni ventana alguna a los lados" (Obras de Mengs, p. 287). Otras veces, la reformulación demuestra su habilidad como traductor y conocedor de la terminología especializada:

[...] los quales hallaron el modo de expresar los diferentes planos y escorzos, esto es, lo que en términos facultativos llaman los Italianos avanti-indietro, [...] (Obras de Mengs, p. 308).

[...] y esto es lo que yo llamo subir los colores hasta cerca del blanco en las luces, y baxarlos hasta tocar el negro en las sombras en la delantera del quadro (Obras de Mengs, p. 102).

Algunos ejemplos de esto se proporcionan en nota, donde se refiere el origen de las voces que se utilizan e incluso, a veces, se justifica su uso por no haber equivalente en español:

Por Bambochada se entiende un asunto bajo, plebeyo y ridículo. Viene este nombre de un cierto Pedro Laar, Pintor Flamenco, feo y corcobado, que en el siglo antecedente pintaba estas cosas en Roma, donde le pusieron por apodo el Bambocho. (Obras de Mengs, p. XXX, n. 1).

No hay voz en nuestra lengua que explique lo que es en Pintura cargado y caricatura, y por eso uso la voz Italiana. Cargar una figura es señalar más allá de la verdad las partes imperfectas y defectuosas: como por exemplo, si un hombre tiene la nariz un poco grande, hacérsela grandísima, y monstruosa. De ello resulta una caricatura, esto es, una cosa ridícula. Un contorno, o una parte qualquiera que debe señalarse suavemente, si se hace con más fuerza de la necesaria, se llama un contorno cargado (Obras de Mengs, p. 33, n. 1).

${ }^{147}$ D. A. de Robledo (1694), p. 314. 
Indudablemente relacionado con el proceso de traducción, el elemento italiano se muestra como el más influyente a lo largo de toda la obra. No solo hay muchos préstamos entre los neologismos del siglo XVIII de las Obras de Mengs, sino que el libro entero está impregnado de esta influencia. Al uso de voces italianas, giros, calcos semánticos y las explicaciones de Azara, muy consciente, como hemos visto, de estar utilizando extranjerismos, se unen a las continuas alusiones a la cultura y modos de expresión de esta procedencia. Por otra parte, resulta interesante constatar que de los nueve neologismos del siglo XVIII que consideramos de posible origen italiano, solo uno (secatura) no es terminológico, lo que significa que el peso específico de la lengua teórico-artística es cultural. El uso del préstamo secatura, como ocurre con gofo o zócolo, apunta a una costumbre debida probablemente al uso de la lengua, las lecturas y, posiblemente, por cruces en los momentos en que Azara traduce desde este idioma.

3.2. Con respecto al elemento léxico es significativo el grupo de voces cultas que datan de todas las épocas de la historia del español, siendo a partir de fines del siglo XV y comienzos del XVI cuando los términos propios del Arte empiezan a ser numerosos. Así, siguiendo la tendencia del idioma iniciada en el siglo XV, y consolidada en los Siglos de Oro, muchos de los neologismos anotados serán neolatinismos o neohelenismos (anacronismo, colosal, elástico, elíptico, oblicuidad, octangular, oleoso, omisible, opacidad, semicírculo, semidiáfano, semidiámetro), latinismos (corpúsculo monumento, ornamento, purpúreo, reflexión, terso, transparente) o helenismos (alabastro, cinabrio, diáfano, elipse, monótono, prisma), rescatados del olvido en ciertos casos. Esta lista deja patente que la necesidad de creación léxica por esta vía no se constriñe a la realidad de la lengua de especialidad, sino que es una necesidad de la lengua culta en general (valgan abolición, acrimonia, afectación, colosal, monótono, omisible, predilección, panegírico, como ejemplos de ello). En algunos casos, el intento creativo, como el de octangular, tiene que contender con un término bien arraigado, si bien de evidente sabor popular, como lo fue en esta tradición textual ochavado.

3.3. En el apartado relativo a la creación léxica patrimonial, en este texto de fines del siglo XVIII los procedimientos se muestran útiles y ágiles. El sufijo -ista para la creación de derivados denominales que indican oficio da una muestra de su vitalidad en mosaiquista, tallista y retratista. De igual modo, el sufijo -ismo, que produce sustantivos con el sentido de doctrina (ya sea filosófica, científica o social), nos lega los vocablos goticismo y rigorismo, que designan actitudes de tendencia doctrinal. Entre los derivados que crean términos propios del oficio del pintor, rastreamos en las Obras de Mengs las palabras descostradura, lapicero y paleta (este último formado con el sufijo - eta cuyo origen no es patrimonial), junto a muchos otros: bastidor, cartón, copista, descorrección, diseñador, encolar, envilecimiento, espinazo, explayar(se), largura, menudencia, pastoso, pincelada, 
porosidad, portada, prendimiento, realzar, redondez, refinar, repintar, retocar, retoque, revestir, risueño, rompimiento, ropaje, sobrepuerta, etc., de entre los que sobresalen los derivados relativos al campo semántico del color: blanquizco, ennegrecer, negrizco, sanguino, rojizo, etc.

3.4. Respecto de los cambios semánticos y las adquisiciones de nuevos valores significativos en palabras de todos los orígenes para completar el léxico de las Artes, queda patente que es un procedimiento básico. Hemos podido estudiar los términos desmayado, linterna, masa, plano, plantado, punzón y subido, y también los galicismos dieciochescos desmayado o gabinete, así como el movimiento semántico del término de procedencia árabe laca, comprobando en todos los casos cómo la nueva acepción provee de un significado esencial para cubrir la evolución de las disciplinas. Recordemos la adopción del sentido 'lámina de acero en cuya superficie está grabado en relieve el ojo de una letra o signo, y que se utiliza para la obtención de una matriz que sirve para fundir una letra, signo o viñeta' de la voz punzón para designar una parte de la imprenta, "recién inventada entonces con tanta utilidad de la literatura y del comercio" (Obras de Mengs, p. 263).

3.5. Respecto a las novedades léxicas del siglo XVIII, como hemos podido comprobar, muchas son neolatinismos y neohelenismos comunes a los demás idiomas europeos cuyo origen está en la influencia mutua de las lenguas modernas; así: anacronismo, colosal, directriz, elástico, elipse, monótono-monotonía, goticismo y rigorismo habrían surgido en nuestro idioma mediante lo que Álvarez de Miranda denomina "creación inducida".

Por otra parte, se ha tenido en cuenta la distinción teórica que delimita el primer español moderno a finales del siglo XVII (alrededor de 1675), por lo que anacronismo (1684, Gonzalo Navarro), corpúsculo (1690, Sigüenza y Góngora), gabinete (cuyo primer testimonio es de 1646 en un texto de Calderón de la Barca, aunque no hay más ejemplos hasta los ya muchos de Feijoo a partir de 1724), pintoresco (1683, Sigüenza y Gongora), prisma (1675, José Zaragoza) y tendinoso (1694, Diego Antonio de Robledo) se consideran voces dieciochescas en el sentido de que van a arraigar en la lengua a lo largo de ese siglo para mostrar su afianzamiento en el siglo siguiente.

En relación con la introducción de novedades en las Obras de Mengs. Hemos hallado en Azara la primera documentación de los italianismos léxicos caricatura, cargado y mosaiquista, el aragonesismo espadachinar; las voces goticismo y semidiáfano y las acepciones terminológicas del ámbito de la Pintura de las voces laca, máquina y maquinoso y pátina. Además de los términos monocromo y monocromista, para designar la corriente pictórica clásica y sus cultores, para cuya explicación y contextualización ha sido necesario recurrir a la recuperación de parcelas de la Historia del Arte. 


\section{Obras citadas}

Alcover, Antoni M. y Francesc de B. Moll: Diccionari català-valencià-balear, Palma de Mallorca, Moll, 1978 [2 ed.].

ALEMANY y BOLUFER, José: Diccionario de la lengua española, Barcelona, Ramón Sopena, 1917. Apud NTLLE.

ALONSO, Martín: Enciclopedia del idioma; diccionario histórico y moderno de la lengua español (siglos XII al XX) etimológico, tecnológico, regional e hispanoamericano, Madrid, Aguilar, 1958.

ALVAR, Manuel: "Sobre el valor de los léxicos particulares" en La lengua como libertad, Madrid, ICI, 1982, pp. 122-139.

Álvarez De MirandA, Pedro: Palabras e ideas: el léxico de la Ilustración temprana en España (1680-1760), Madrid, Real Academia Española, 1992.

ÁlvareZ DE MIRANDA, Pedro: "El léxico español, desde el siglo XVIII hasta hoy", en Historia de la lengua española, R. Cano Aguilar coord., Barcelona, Ariel, 2004, pp. 1037-1064.

AZARA, José Nicolás de: El espiritu de D. José Nicolás de Azara, descubierto en su correspondencia epistolar con Don Manuel de Roda, comp. y prólogo de M. Bourgoin, Madrid, Imprenta de J. Martín Alegría, 1804.

BAtistTI, Carlo y Giovanni Alessio: Dizionario etimologico italiano, 5 vols., Firenze, G. Barberà, 1975.

BAZZI, María: Enciclopedia de las técnicas pictóricas, trad. y vocabulario técnico de R. Santos Torroella, Barcelona-Madrid, Noguer, 1965.

BERGQUIST, Kevin: "Google project promotes public good", University Record on line, University of Michigan, 13 de febrero de 2006. En http://www.ur.umich.edu/0506/Feb13_06/02.shtml. Consulta: 28/7/14.

BLOCH, Oscar y Walther von WARTBURG: Dictionnaire étymologique de la langue française, París, Presses Universitaires de France, 1968 [5ª ed.].

CASTAÑER LÓPEZ, Xesqui: "Analogías, diferencias y transferencias en la terminología artística del siglo XVIII español", Ars longa: cuadernos de arte 22 (2013), pp. 195-210.

Castellanos De Losada, Basilio Sebastián: Historia de la vida de D. José Nicolás de Azara, Madrid, Imprenta de D. Baltasar González, 1850.

Centre National De Resources Textuelles et LexicAles (CNRTL): Ortolang: Le Trésor de la Langue Française informatisé, 2012. En http://www.cnrtl.fr/etymologie/directeur. Consulta: 27/07/2014

Checa Beltrán, José: Pensamiento literario del s. XVIII español: antología comentada, CSIC, Madrid, 2004.

CINELLI, Noemí: "«Sobria claridad y arcaica pureza». Reflexiones sobre el gusto en el Siglo de las Luces. El caso de la Villa Negroni de Roma: modelos e influencias de Mengs y Azara (1777)", en Actas del Simposio Reflexiones 
sobre el Gusto (Zaragoza 2010), Zaragoza, Institución "Fernando el Católico", 2012, pp. 205-219.

CiNELLI, Noemí: "El pintor filósofo y el filósofo pintor. La influencia de la teoría artística de Mengs en los retratos de Goya", en Goya y su contexto: Actas del seminario internacional celebrado en la Institución "Fernando el Católico» los días 27, 28 y 29 de octubre de 2011, Zaragoza, Institución "Fernando el Católico", 2013, pp. 301-315.

ClaVERÍA, Gloria: El latinismo en español, Barcelona, Universitat, 1991.

Clavería, Gloria, "Nuevas perspectivas en el estudio de la investigación del léxico", en Historia del léxico: perspectiva de investigación, G. Clavería, M. Freixas Alás, M. Prat Sabater et al., eds., Madrid, Iberoamericana, Frankfurt, Vervuert, 2012, pp. 13-90.

Clavería, Gloria y $\mathrm{M}^{\mathrm{a}}$ Jesús MANCHO: Estudio del léxico y bases de datos, vol. 7 de Cuadernos de Filología, Universidad Autònoma de Barcelona, 2006.

CNRTL V. Centre National de Resources TeXtuelles et LeXicales (CNRTL): Ortolang: Le Trésor de la Langue Française informatisé, 2012.

COLÓN DOMENECH, Germán: "Catalanismos", en Enciclopedia Lingüistica Hispánica. Tomo II: Elementos constitutivos. Fuentes, Madrid, CSIC, 1967, pp.193-238.

COROMINES, Joan: Diccionari etimologic i complementari de la llengua catalana, con la colaboración de Joseph Gulsoy i Max Cahner, 10 vols., Barcelona, Curial Edicions Catalanes, Caixa de Pensions "La Caixa", 1980-1991.

Coromines, Joan y José PASCUAL: Diccionario Crítico Etimológico Castellano e Hispánico (DCECH), 6 vols., Madrid, Gredos, 1980-1991.

CORRIENTE, Federico: Diccionario de arabismos y voces afines en iberromance, Madrid, Gredos, 1999.

CORRIENTE, Federico: Dictionary of Arabic and Allied Loanword: Spanish, Portuguese, Catalan, Galician and Kindred Dialects, BRILL, 2008.

COVARRUBIAS, Sebastián de: Tesoro de la lengua castellana o española. Según la impresión de 1611, con las adiciones de Benito Remigio Noydens, publicadas en la de 1674, ed. de Martín de Riquer, Barcelona, ed. Alta Fulla. 1943.

CRESPO, Rafael José de: Don Pápis de Bobadilla, Zaragoza, Polo y Monge, 1829.

DAVIES, Mark: Corpus del Español: 100 million words, 1200s-1900s. 2002- . En http://www.corpusdelespanol.org. Consulta: 1/8/2014.

Devoto, Giacomo: Avviamento alla etimologia italiana: dizionario etimologico, Firenze, Felice le Monnier, 1989 [2 ${ }^{\mathrm{a}}$ ed.].

DÍAZ, Juan y Francisco LORENTE: Nuevo diccionario manual latino-castellano: compuesto con presencia de los más acreditados así nacionales comno estrangeros [...] (Google eBook), Madrid, Imprenta de Pedro Sanz, 1836.

DomíngueZ, Ramón Joaquín: Nuevo suplemento al Diccionario Nacional o Gran Diccionario Clásico de la Lengua Española, Madrid, Imprenta y Librería Universal de los Sres. Crespo, Martín y Comp., 1869. Apud NTLLE 
DunCan, Robert M.: "Adjetivos de color en el español medieval", Anuario de Estudios Medievales, 5 (1968), pp. 463-464.

ESEVERRI HUALDE, Crisóstomo: Diccionario etimológico de helenismos españoles, Burgos, Imprenta Aldecoa, 1945.

FAJARDO AGUIRRE, Alejandro: "La datación del léxico en la léxicografía histórica del español", en Rafael Arnold y Jutta Langenbacher-Liebgott eds., Cosmos léxico. Contribuciones a la lexicología y a la lexicografía hispánicas, Frankfurt am Main, Peter Lang, 2006, pp. 51-60.

FAJARDO AGUIRRE, Alejandro: "La lexicografía histórica actual: tradición y nuevas perspectivas", en Assí como es de suso dicho: estudios de morfología y léxico en homenaje a Jesús Pena, San Millán de la Cogolla, CiLengua, 2012.

GAFFIOT, Félix: Dictionnaire Latin Français, París, Hachette, 1934.

GARCía GARRosA, María Jesús y Francisco LAFARGA: El discurso sobre la traducción en la España del s. XVIII. Estudio y antología, Kassel, Reichenberger, 2004.

GARCÍA JÁUREGUI, Carlos: La formación de la terminología anatómica en español (1493-1604). Tesis doctoral, Salamanca, Universidad, 2010.

García SAlinero, Fernando: Léxico de los alarifes de los Siglos de Oro, Madrid, RAE, 1968.

García-Godoy, Ma Teresa (ed.), El español del siglo XVIII. Cambios diacrónicos en el primer español moderno, Berna, Peter Lang, 2012.

GARriga, Cecilio: "Notas sobre la historia de la voz átomo", Revista de Investigación Lingüística, 11 (2008), pp. 95-124

GASPAR MARISTANY, José y José ROIG OLIVERAS, Biblioteca ilustrada de Gaspar $y$ Roig. Diccionario enciclopédico de la lengua española: con todas las voces, frases, refranes y locuciones usadas en España y las Américas españolas [...], Madrid, Imprenta de Gaspar y Roig, 1855. Apud NTLLE.

Glare, Peter G. W. (ed.): Oxford Latin Dictionary, Oxford, Clarendon Press, 2005. GRASSI, Luigi y Mario PEPE: Dizionaro dei Termini Artistici, Milano, TEA, 1994.

HARPER, Douglas: Online Etymology Dictionary, 2001-2014. En http://www.etymonline.com/ Consulta: 1/8/2014.

HIDALGO, Manuel: "Elogio de la Antigüedad", El Mundo, 17 de enero de 2014. En http://www.elmundo.es/cultura/2014/01/17/52d8ec5fca4741d0798b456a.html. Consulta: 18/06/2014.

LÓPEZ MORA, Pilar: "Caracterización lexicológica y normas de transcripción. La especificidad de los textos teórico-artísticos de la Edad Moderna" en Teoría y literatura artística en la sociedad digital Construcción y aplicabilidad de colecciones textuales informatizadas, N. Rodríguez Ortega, ed., Gijón, TREA, 2010, pp. 195-224.

MACHADO, José Pedro: Diccionario etimológico da lingua portuguesa: com a mais antiga documentação escrita e conhecida de muitos dos vocábulos estudados, 3 vols., Lisboa, Confluencia, 1967. 
MALKIEL, Yakov: "Préstamos y cultismos", Revue de Linguistique Romane XX (1957), pp. 1-61.

MARTín FERNÁNDEZ, Ma Isabel: Préstamos semánticos en español, Cáceres, Universidad de Extremadura, 1988.

MARTín ZORRAQUINO, Ma Antonia: "Formación de palabras y lenguaje técnico", Revista Española de lingüistica 27 (1997), pp. 317-339.

MARTINELL, Emma: "Expresión lingüística del color en el «Lapidario» de Alfonso X", Cahiers de linguistique hispanique médiévale 11 (1986), pp. 133-149.

Morales y Marín, José Luis: Diccionario de Términos Artísticos, Zaragoza, Octavio y Félez, 1982.

MORET I COSO, Hèctor: "Lèxic de l'Aragó catalanòfon al Diccionari Aguiló i al Diccionari català-valencià-balear", Alazet 5 (1993), pp. 91-126.

NeBRIJA, Antonio de: Vocabulario español-latino, Salamanca, [Impresor de la Gramática castellana], 1495. Apud NTLLE

Nieto, Lidio y Manuel Alvar EZQUeRRA, Nuevo Tesoro Lexicográfico del español (s. XIV-1726), 11 vols., Madrid, Arco Libros, 2007.

Nocentini, Alberto: Dizionari elettronici elexico.com. l'Etimologico: Vocabolario de la lingua italiana, Le Monnier, 2010.

NTLLE V. REAL ACADEMIA EsPaÑolA: Nuevo tesoro lexicográfico de la lengua española (NTLLE).

NÚÑEZ DE TABOADA, Melchor Manuel: Diccionario Francés-Español y EspañolFrancés, Volumen 1 (Google eBook), París, Brunot-Labbé, 1820.

OCTAVIO DE TOLEDO, Álvaro S.: "Un nuevo esquema adversativo en el primer español moderno (h. 1675-1825)", en Actas del VII Congreso Internacional de Historia de la Lengua Española (Mérida (Yucatán), del 4 al 8 de septiembre de 2006), Vol. II, Madrid, Arco Libros, 2008, pp. 877-907.

PAGÉS, Aniceto: Gran diccionario de la lengua castellana, autorizado con ejemplos de buenos escritores antiguos y modernos [...]. Continuado y completado por José Pérez Hervás. Tomo cuarto. Barcelona, 1925. Apud NTLLE.

PARDO ASSO, José: Nuevo diccionario etimológico aragonés, Zaragoza, Imp. del Hogar Pignatelli, 1938.

PHARIES, David: Diccionario etimológico de los sufijos españoles, Madrid, Gredos, 2002.

PRATI, Angelico: Vocabolario etimologico italiano, Milano, Garzanti, 1970.

REAL ACADEMIA ESPAÑOlA: Diccionario de la lengua castellana, en que se explica el verdadero sentido de las voces, su naturaleza y calidad, con las phrases o modos de hablar, los proverbios o refranes, y otras cosas convenientes al uso de la lengua [...]. Compuesto por la Real Academia Española, 3 vols., Madrid, Imprenta de Francisco del Hierro, 1726-1739. Apud NTLLE.

REAl ACADEMIA EsPañola: Diccionario de la lengua española (DRAE), Madrid, Espasa, 2014 [ $23^{\mathrm{a}}$ ed.]. 
REAL ACADEMIA ESPAÑola: Nuevo tesoro lexicográfico de la lengua española (NTLLE) En http://ntlle.rae.es/ntlle/SrvltGUILoginNtlle. Consulta: 1/8/14.

RODRÍGUEZ NAVAS Y CARRASCO, Manuel: Diccionario general y técnico hipanoamericano, Madrid, Cultura Hispanoamericana, 1918. Apud NTLLE.

RODRÍGUEZ ORTEGA, Nuria: "Un proyecto de estudio en la Historia del Arte: Presentación y descripción de un modelo de tesauro pictórico artístico (I)", Boletín de Arte 20 (1999), Universidad de Málaga, pp. 395-422.

RODRÍGUEZ ORTEGA, Nuria: "La terminología artística italiana como factor configurador del vocabulario teórico-crítico español. Algunos ejemplos de transferencia y manifestación textual", en Libros con arte. Arte con libros, Cáceres, Junta de Extremadura, Universidad de Extremadura, 2007, pp. 617628.

RODRÍGUEZ ORTEGA, Nuria: "El Corpus informatizado de textos artísticos ATENEA. Nuevos horizontes en la documentación, difusión e investigación del Patrimonio Cultural", en Estudios de historia del arte: centenario del Laboratorio de Arte (1907-2007). Vol. 1, Universidad de Sevilla, 2009, pp. 269-284.

SALVÁ, Vicente: Nuevo diccionario de la lengua castellana, que comprende la última edición integra, muy rectificada y mejorada del último de la Academia Española, y unas veinte y seis mil voces, acepciones, frases y locuciones, entre ellas muchas americanas [...], París, 1846. Apud NTLLE.

SALVADOR, Gregorio: Incorporaciones léxicas en el español del siglo XVIII, Oviedo, Cátedra Feijoo, 1973.

SÁNCHEZ CANTÓN, Francisco Javier: Mengs en España, conferencia dada el 5 de abril de 1927 Madrid, Centro de Intercambio Intelectual Germano-Español, 1927.

SÁNCHEZ EsPinOSA, Gabriel (ed.): Las Memorias del ilustrado aragonés José Nicolás de Azara, Institución Fernando el Católico (C.S.I.C), 2000.

TElleCheA IDÍGORAS, José Ignacio: "Azara y la edición de las obras de A.R. Mengs. Interpolaciones de Llaguno y Amírola", Academia: Boletín de la Real Academia de Bellas Artes de San Fernando, 35 (1972), pp. 45-68.

TERLINGER, Jan: "Italianismos", en Enciclopedia Lingüistica Hispánica. Tomo II: Elementos constitutivos. Fuentes, Madrid, CSIC, 1967, pp. 263-305.

TERreros Y PANDO, Esteban de: Diccionario castellano con las voces de las ciencias y artes y sus correspondientes en las tres lenguas francesa, latina e italiana [...], 3 vols, Madrid, Viuda de Ibarra, 1786-1788.

VARELA MERINO, Elena: Los galicismos en el español de los siglos XVI y XVII, 2 vols., Anejos de la Revista Española de Filología 100, Madrid, CSIC, 2009.

VERDONK, Robert: "Cambios en el léxico del español durante la época de los Austrias", en Historia de la lengua española, R. Cano Aguilar, coord., Barcelona, Ariel, 2004, pp. 895-916. 
VIEIRA, Fray Domingo Luis: Grande Diccionario portuguez ou Thesouro da lingua portugueza (Google eBook), Porto, Ernesto Chardon e Bartholomeu H. de Moraes, 1878.

ZEROLO, Elías: Diccionario enciclopédico de la lengua castellana, París, Garnier hermanos, 1895. Apud NTLLE. 


\section{Fuentes documentales}

ABIZANDA Y BROTO, Manuel: Documentos para la historia artística y literaria de Aragón (Google eBook), Zaragoza, Tip. La Editorial, 1915.

ACCADEMIA DELla CRUSCA: Vocabolario degli academici della Crusca, Florencia, Lorenzo Basegio, 1724.

ANÓNIMO, Gaceta de Madrid. Números 53-104 (Google eBook), Madrid, Imprenta Real, 1791.

AZARA, José Nicolás de: Epistolario (1784-1804) (Google eBook), ed. de María Dolores Jimeno Puyol, Castalia, Barcelona, 2012.

BOSARTE, Isidoro: Observaciones sobre las bellas artes entre los antiguos hasta la conquista de Grecia por los romanos[...] (Google eBook), Madrid, Oficina de don Benito Cano, 1791.

Carducho, Vicenzo: Diálogos de la Pintura, ed. de Calvo Serraller, Madrid, Turner, 1979.

CÉSPEDES, Pablo de: "«Discurso de la Comparación de la Antigua y Moderna Pintura y Escultura» de Pablo de Céspedes, dirigido a Pedro de Valencia (1605)", en Escritos de Pablo de Céspedes. Edición crítica, ed. de J. Rubio Lapaz y F. Moreno Cuadro, Diputación de Córdoba, 1998, pp. 241-298.

CORDE V. REAL ACADEMIA ESPAÑOLA: Banco de datos (CORDE).

CREA V. REAL ACADEMIA ESPAÑola: Banco de datos (CREA).

CRESPO, Rafael José de: Don Pápis de Bobadilla, Zaragoza, Polo y Monge, 1829.

DAVIES, Mark: Corpus del Español: 100 million words, 1200s-1900s. 2002- . En http://www.corpusdelespanol.org. Consulta: 1/8/2014.

DELGADO, Juan José: Historia general sacro-profana, política y natural de las islas del Poniente llamadas Filipinas (Google eBook), Manila, Imp. de El Eco de Filipinas se don Juan Atayde, 1892.

Devoto, Giacomo: Avviamento alla etimologia italiana: dizionario etimologico, Firenze, Felice le Monnier, 1989 [2 ${ }^{\mathrm{a}}$ ed.].

FERNÁNDEZ DE CASTRO, Nicolás: Portugal Convencida con la razon para ser venzida con las catolicas potentissimas armas de D. Felipe IV (Google eBook), Malatestas, 1648.

García De la Huerta, Pedro: Comentarios de la pintura encaústica del pincel (Google eBook), Madrid, Imprenta Real, 1795.

LagUNO, Francisco: Gracias a Dios que en solemnissimo novenario rinde a su Magestad piadosa,el Real Convento de San Felipe... (Google eBook), Madrid, 1718.

LARRAMENDI, Manuel de: Diccionario trilingüe del castellano, bascuence y latín. Tomo I (Google eBook), San Sebastián, Bartolomé Riesgo y Montero, 1745. 
MANJARRÉS, Joseph: Teoría e historia de las Bellas Artes: Principios fundamentales (Google eBook), Barcelona, Librería de Joaquín Verdaguer, 1859.

MAZARREDO SAlAZAR, José de: Rudimentos de táctica naval para instruccion de los oficiales subalternos de Marina (Google eBook), Madrid, Imprenta Real, 1776.

MeNGS, Raphael: Obras de Don Antonio Rafael Mengs, primer pintor de cámara del rey, publicadas por Don Joseph Nicolás de Azara, Madrid, Imprenta Real, 1797 [2 $2^{\mathrm{a} e d}$.].

Mor De Fuentes, José: Julia o la Nueva Heloisa. Por Juan Jacobo Rousseau; puesta en castellano por D. José Mor de Fuentes, Barcelona, Imprenta de A. Bergnes, 1836-37.

NAVArro, Gonzalo y José NAVARro CAStellanos: Discursos politicos, y morales en cartas apologeticas, contra los que defienden el vso de las comedias modernas que se representan en España[...] (Google eBook), Madrid, Imprenta Real, 1684.

Palomino de CASTRO Y Velasco, Antonio: El museo pictórico y escala óptica [...], tomo I, Madrid, Lucas Antonio de Bédmar, 1715.

PALOUZE, Mor: Secretos novisimos de artes y oficios, tomo I (Google eBook), Imp. de D. Manuel Sauri, 1841.

Ple V. Seminari de Filologia i Informàtica, Portal del Léxico Hispánico (PLE).

Real ACAdemia de Bellas ARTes De SAn Fernando: Distribución de los premios concedidos por el rey a los discípulos de las tres nobles artes, hecho por la Real Academia de San Fernando en la junta publica del 24 de Julio de 1802 (Google eBook), Viuda de Ibarra, Madrid, 1802.

Real ACADEMIa Española: Banco de datos (CORDE) [en línea]. Corpus diacrónico del español. En http://www.rae.es. Consulta: 1/8/14.

Real ACAdemia Española: Banco de datos (CREA) [en línea]. Corpus de referencia del español actual. En http://www.rae.es. Consulta: 1/8/14.

Real Museo de Pintura y Escultura, Catálogo de los cuadros del Real Museo de Pintura y Escultura de S.M.: redactado con arreglo á las indicaciones del director actual de este real establecimiento (Google eBook), Don J.M. Alonso, 1850 ( $3^{\mathrm{a} e d}$.).

Robledo, Diego Antonio de: Compendio cirurgico vtil y prouechoso a sus professores (Google eBook), Valencia, Imp. Vicente Cabrera, 1694.

Santos, Fray Francisco de los: Descripción breve del Monasterio de San Lorenzo El Real del Escorial. Única maravilla del mundo, ed. facs. de la de 1657, Móstoles, Almiar, 1984.

Seminari de Filologia i Informàtica, Portal del Léxico Hispánico (PLE), Universitat Autónoma de Barcelona. En http://www.portaldelexico.es/ Consulta: 1/8/2014. 
TESAURO, Emanuel: Filosofía Moral (Google eBook), Madrid, Manuel Román, 1723 [1 ${ }^{\mathrm{a} e d .}$ 1715].

VALBUEnA, Manuel de: Diccionario universal latino-español (Google eBook), Madrid, Imprenta Real, 1826 [5 $5^{\mathrm{a}}$ ed.]. 